\title{
Reflexiones para la política sectorial de salud en Perú a partir de las Cuentas Nacionales de Salud
}

\author{
Margarita Petrera*
}

\begin{abstract}
RESUMEN
El artículo tiene como objetivo ofrecer a los responsables de la rectoría en salud las reflexiones de política sectorial que se derivan del estudio de las Cuentas Nacionales de Salud (1995-2014) del país. Si bien el país ha incrementado el gasto en salud del 4,4 al 5,2\% del PIB, el «gasto de bolsillo de los hogares» constituye el 33\% del total del financiamiento, lo que requiere modificar su composición. Se advierten problemas en la capacidad de respuesta del sistema de salud al mayor financiamiento y gasto público, que se vinculan a temas de rectoría y organización de la prestación. Si bien el aseguramiento se ha incrementado, las restricciones en la oferta impiden que las personas afiliadas a algún tipo de seguro puedan, en su gran mayoría, acceder a los servicios de salud. El cambio más importante en la gestión pública del gasto es la descentralización, mientras que en la gestión privada lo es la integración vertical de prestadores y aseguradoras, dando surgimiento a un agente nuevo: el inversionista en salud.

Se concluye que el país se encuentra, todavía lejos de poder financiar la meta de universalización del acceso en salud. Las recomendaciones para mejorar el financiamiento, mancomunación y el gasto apuntan, casi simultáneamente, a generar un mayor financiamiento público y de la seguridad social dentro de una activa política de mejora de la eficiencia global e institucional del sistema, la que debe redundar tanto en mejores resultados sanitarios, como en la disminución drástica del gasto de bolsillo. Por tanto, el buen éxito de la función financiera está íntimamente relacionado con el buen desempeńo de las funciones de rectoría y prestación.
\end{abstract}

Palabras clave: Cuentas Nacionales de Salud, seguridad social.

Clasificación JEL: I13, I18

* Este artículo fue financiado por la Organización Panamericana de la Salud - Organización Mundial de la Salud (OPS/OMS). La autora agradece muy especialmente los valiosos aportes de Claudia Pescetto, Gustavo Vargas y Pedro Ypanaqué, funcionarios de dicha organización.

** Docente en la Universidad Peruana Cayetano Heredia. Magíster en Economía por la PUCP y doctora en Salud Pública por la Universidad Peruana Cayetano Heredia. Ha sido funcionaria de la Organización Panamericana de la Salud/Organización Mundial de la Salud. 


\title{
Reflections for a Sectoral Health Policy for Peru Based for on the National Health Accounts
}

\begin{abstract}
The objective of this article is to offer those responsible for the Peruvian health rectorship reflections on sectoral policy derived from the study of the country's National Health Accounts (1995-2014). While it is true that the country has increased its spending on health from 4.4 to $5.2 \%$ of GDP, $33 \%$ of its total funding comes from household «out of pocket expense», which indicates that change is necessary. Problems in the responsiveness of the health system to greater funding and public expenditure, linked to issues of rectorship and service organization, are apparent. Although there has been an increase in numbers of people with insurance, the restrictions on what is covered prevent the great majority of these people accessing health services. The most important change in the public administration of expenditure has been decentralization, while in the private administration it has been the vertical integration of providers and insurers, which has given rise to a new agent: the health investor.

The article concludes that the country is still far from being able to finance the aim of universal access to health care. Recommendations to improve the funding, joint administration, and expenditure point, almost simultaneously, towards generating greater public funding and social security within an active policy aimed at improving the global efficiency and institutionality of the system, which should work to the advantage of better health results as well to drastically decrease household pocket expense. Therefore, the success of the financial function is closely related to the adequate performance of the functions of rectorship and provision.
\end{abstract}

Keywords: National Health Accounts, Social Security System.

JEL Codes: I13, I18

\section{INTRODUCCIÓN}

La publicación Cuentas Nacionales de Salud, Perú 1995-2012 (Minsa, 2015) ofrece además de un estudio de las cuentas financieras del país durante dieciocho años continuos —una de las series más largas de América Latina—, su interacción con los patrones de aseguramiento en salud y acceso efectivo a los servicios de salud de la población según niveles socioeconómicos, lo que constituye un importante y especial documento para analizar los resultados que se ofrecen. Es objetivo de este artículo presentar las reflexiones de política sectorial que se derivan del estudio anteriormente mencionado. Ellas están dirigidas, principalmente, a los responsables de la rectoría en salud, sobre todo en el actual contexto ad portas de iniciarse una nueva gestión gubernamental.

El Perú, ubicado en la costa del Pacífico de Sudamérica, contaba en 2015 con 31 millones de habitantes. Clasificado como un país de renta media gracias a un largo ciclo de crecimiento económico, desde inicios de la década de 2000 hasta 2013 — con el 6\% 
de promedio anual - y acompañado de un conjunto de políticas de lucha contra la pobreza, el país ha logrado (2015) una disminución de la misma, en términos de línea de pobreza monetaria, al 14,5\% en el ámbito urbano y al 45,2\% en el rural, lo que, además, evidencia la persistencia de la desigualdad social. La actual situación y perspectivas de menor crecimiento económico, así como la anomía debido al incremento de conflictos sociales vinculados a la explotación minera, al proceso inconcluso de descentralización y a la inseguridad ciudadana, se han convertido en urgencias en el debate político y económico, que amenazan con la reversión de lo avanzado en el combate contra la pobreza y dificultan la revisión y profundización de políticas de desarrollo humano de mediano y largo plazo como son las de educación, salud y nutrición. Se considera, por tanto, relevante contribuir en este tema vinculando el desempeño de los principales actores públicos, privados y hogares involucrados desde el financiamiento hasta el acceso a los servicios de la salud con el proceso económico y el desarrollo y retos de la función gobierno en el sector salud en el Perú.

Específicamente en cuanto a los servicios de salud, tanto la expansión del aseguramiento público en salud, la reestructuración y expansión de la oferta pública y del mismo sistema de salud, y posteriormente el desarrollo de alianzas con el sector privado han sido planteados por diversos gobiernos desde la segunda mitad de la década de 1990 como objetivos estratégicos para la universalización del acceso en salud (Minsa, 2013; Acuerdo Nacional, 2014). Por ello, el Ministerio de Salud (Minsa) como ente rector del sector requiere contar no solo con información sobre los logros/retos de esta política a través de la evolución de resultados de los flujos de financiamiento, gasto, acceso efectivo a los servicios de salud y sus vínculos con el aseguramiento en salud, sino que además debe ser capaz de utilizar dicha información como insumo para sus decisiones y como instrumento de comunicación, diálogo y concertación para una efectiva rectoría sanitaria y una gestión transparente del sector, que debe ser confirmada a través de resultados que apunten a verificar la efectividad de aseguramiento en el acceso a los servicios y en la disminución del "gasto de bolsillo», sobre todo de quienes presentan mayores necesidades de salud en condiciones económicas adversas.

\section{MATERIAL Y MÉTODOS}

El objeto de estudio de las cuentas nacionales de salud (CCNNS) es la estimación del gasto en salud, definido como el resultado del consumo de bienes y servicios de salud ${ }^{1}$. Desde un enfoque funcional, el concepto de gasto incluye el consumo de recursos económicos (tales como personal, insumos, sistemas administrativos y logísticos, entre otros)

\footnotetext{
1 Este artículo fue financiado por la Organización Panamericana de la Salud - Organización Mundial de la Salud (OPS/OMS). La autora agradece muy especialmente los valiosos aportes de Claudia Pescetto, Gustavo Vargas y Pedro Ypanaqué funcionarios de dicha organización.
} 
destinados a la promoción ${ }^{2}$, prevención y prestación del servicio de salud, así como a la formación bruta de capital requerida para las actividades de salud. Incluye La administración, capacitación y entrenamiento de los recursos humanos en salud que se encuentren por brindar o brindando servicios de salud (sea en la rectoría o prestación de servicios), y la investigación aplicada en salud. Dado que las CCNNS se centran en la producción de servicios de salud, se han excluido gastos denominados "No Salud» en el Minsa, en Regiones y en EsSalud, los cuales corresponden a actividades de saneamiento, nutrición (excepto alimentos para hospitalizados, personal y complementos al tratamiento de enfermedades), pensiones y los gastos de administración de los fondos de aseguramiento en salud. No se incluye la formación técnica y universitaria para formar técnicos y profesionales en salud.

Como se indica en la introducción del estudio, complementar el desarrollo de los flujos financieros con la identificación de patrones de aseguramiento, acceso y gasto de los hogares según niveles socioeconómicos, hace posible interactuar el gasto de los diversos prestadores y el de los hogares con el acceso a los servicios de salud y los problemas que dificulten este acceso. Las fuentes principalmente utilizadas son las estadísticas de la oferta, pública y privada cuando se refieren a montos monetarios, y las bases de datos de la Encuesta Nacional de Hogares elaboradas anualmente por el Instituto Nacional de Estadísticas (ENAHO-INEI) cuando se refieren a los reportes de los hogares. Ambas fuentes han sido compatibilizadas, así como se han actualizados los datos del periodo de estudio 1995-2012, habiéndose incluido en este artículo los años 2013 y 2014 en lo que respecta a la información proveniente de los hogares.

\section{ASIMILANDO LOS RESULTADOS}

\subsection{El gasto en SERVicios de SALUd COMO PORCENTAje Del PBI}

En el periodo 1995-2012 el gasto nacional en servicios de salud, denominado gasto nacional en salud, creció en 126,8\% en nuevos soles de 2007 con lo que la propensión media al gasto en salud subió de 4,4\% a 5,2\% del PIB (Cuadro 1 y Gráfico 1). Esta afirmación usualmente suele conllevar la apreciación sobre la necesidad de gastar más en salud, ya que se está bastante por debajo del promedio latinoamericano $(7,6 \%)^{3}$. No obstante, nuestra propuesta es tratarlo como una oportunidad para decidir cómo es que un pais quiere crecer en la prestación de servicios de salud para cumplir con el objetivo de universalización de la atención de la salud.

\footnotetext{
2 No incluye el gasto en la difusión de mejora en los hábitos de vida y prevención de accidentes que efectúan otros sectores como educación vivienda, justicia, saneamiento, excepto si el sector salud participa en su financiamiento y en el monto en que contribuye.

3 World Development Indicators 2012, citado por el Ministerio de Salud. Lineamientos y Medidas de Reforma del Sector Salud, p. 14, julio 2013.
} 


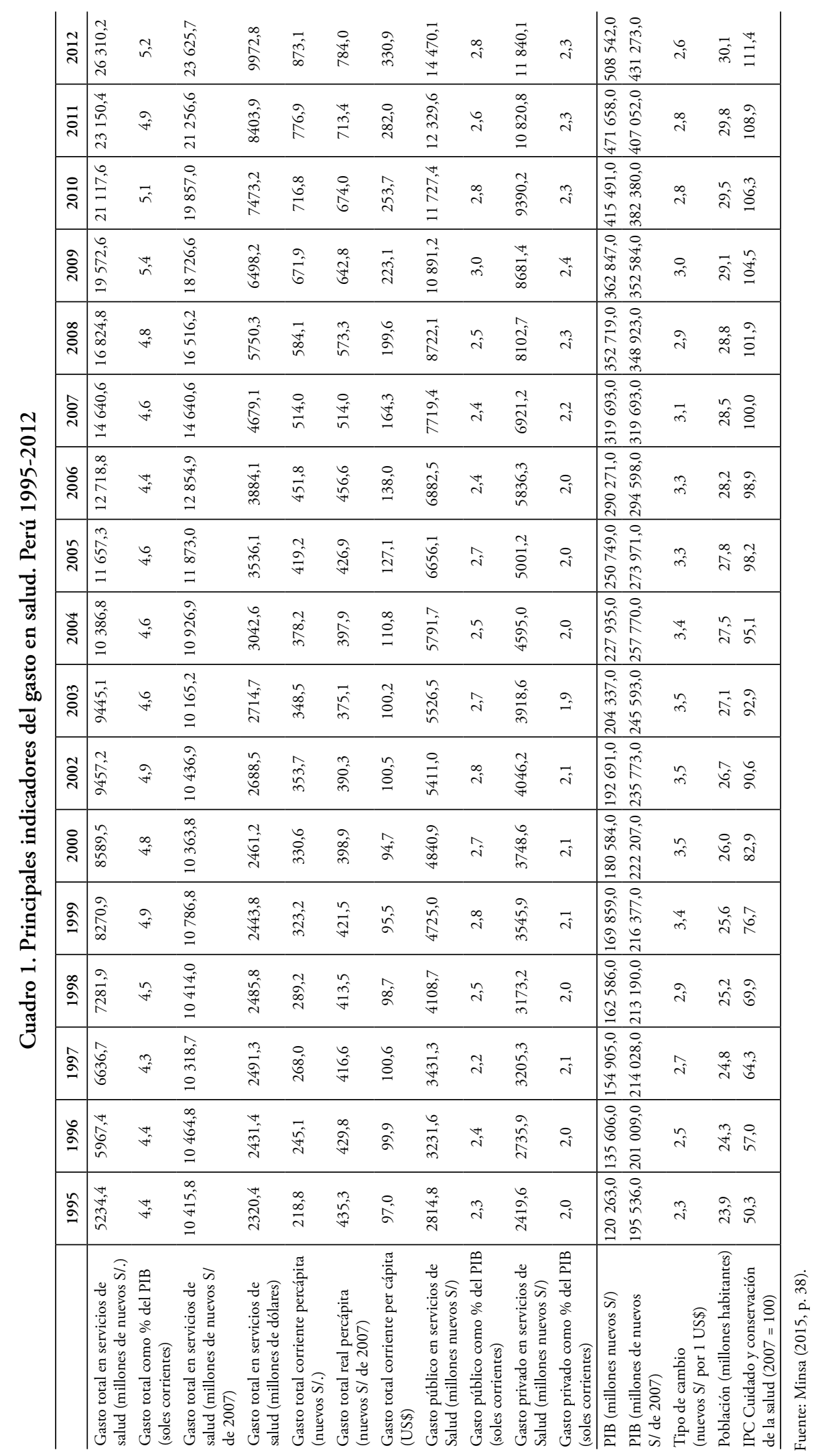


Gráfico 1. Evolución del PIB y gasto en salud. Perú 1995-2012

(Millones de nuevos soles)

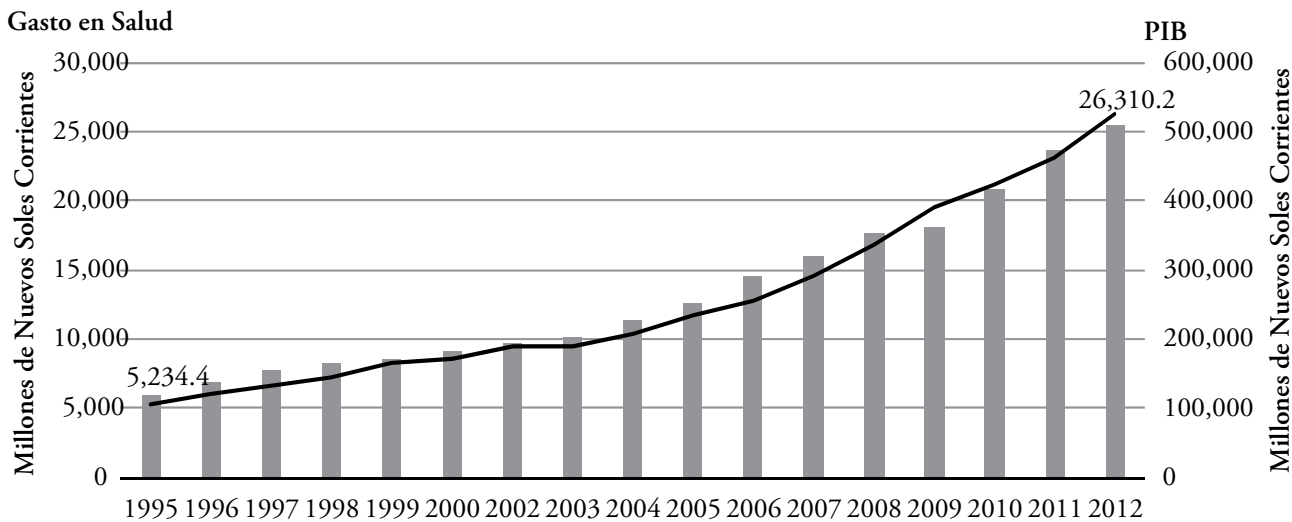

\subsection{El gasto REAL EN SALUd}

La capacidad de compra de bienes y servicios del gasto en salud es denominada gasto real en salud, y se obtiene dividiendo el gasto monetario anual entre el índice anual de precios del rubro "Cuidado y conservación de la salud» proporcionado por el INEI ${ }^{4}$. Este rubro tiene 4 componentes: "Productos medicinales y farmacéuticos», "Aparatos y equipos terapéuticos», "Servicios médicos y similares» (tarifas, honorarios, remuneraciones), «Hospitalización y similares» y «Seguro contra accidentes y enfermedades». El componente «Productos medicinales y farmacéuticos» disminuyó su crecimiento desde 2003, posiblemente debido al aumento paulatino en el uso de medicamentos genéricos lo que contribuyó a disminuir el índice de precios del «Cuidado y conservación de la salud». Los «Gastos por hospitalización» y «Aparatos y equipos terapéuticos» lideran la tendencia creciente en los últimos años (Gráfico 2).

\footnotetext{
4 No obstante, este índice presenta algunas restricciones que pueden ser resumidas en la existencia de una canasta muy acotada en cada uno de los componentes del rubro la que el INEI se encuentra revisando. La canasta debe ser ampliada para la incorporación de nuevos productos, tanto por innovación tecnológica/ marketing como por la evolución del aseguramiento privado (Minsa, 2015, cita 11).
} 
Gráfico 2. Evolución de los componentes del índice de precios del Cuidado y conservación de la salud. Perú 1995-2012

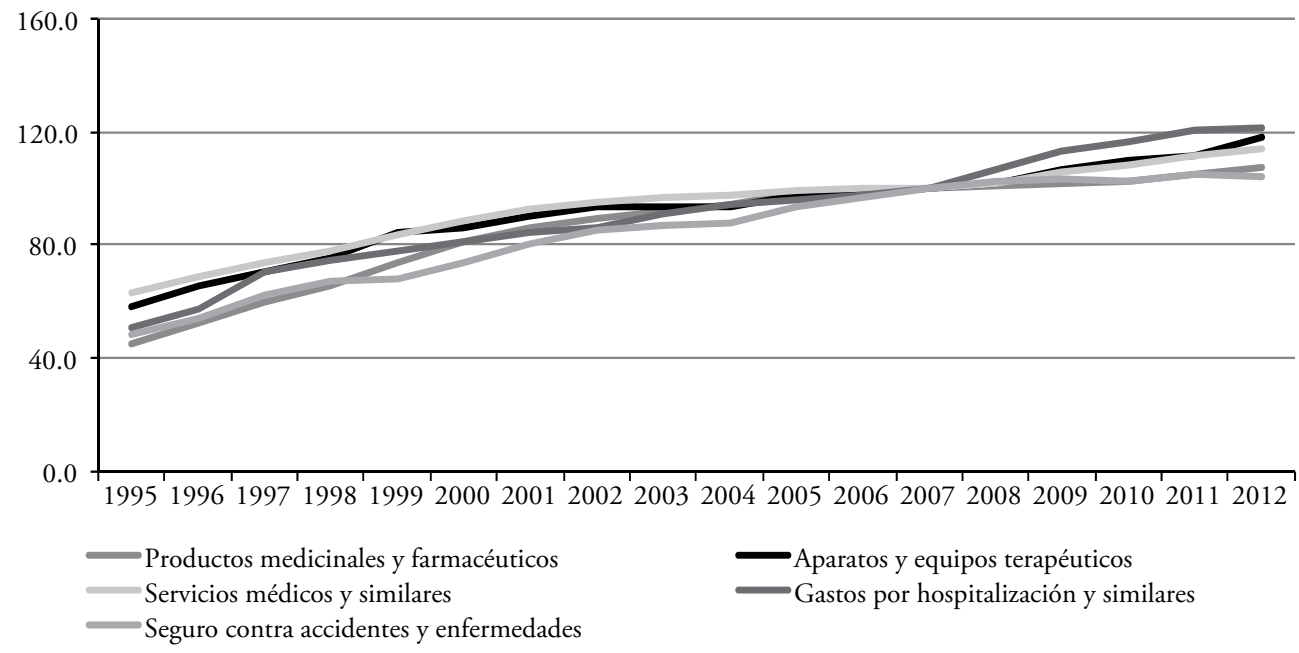

Elaborado a partir de Minsa (2015, p. 42).

\subsection{Matriz de Flujos FinanCieros}

Los establecimientos del Minsa y Regiones se financian principalmente con recursos del gobierno (principalmente recursos ordinarios) y en menor medida con financiamiento de los hogares (tarifas por compra de servicios, pruebas y medicamentos) ${ }^{5}$. En los establecimientos de EsSalud la gran mayoría de recursos provienen de los aportes sobre la base del trabajo declarado. En el sector privado los prestadores se financian directamente con recursos de los hogares y/o a través de seguros privados y en menor medida de empleadores que contratan seguros para sus trabajadores. Los prestadores privados no lucrativos reciben también recursos de cooperantes internacionales y donaciones. Hasta el ańo 2012 la modalidad de compra de servicios privados con financiamiento público era casi inexistente, limitándose a algunas compras de EsSalud. La compra directa en farmacias y boticas la realizan los hogares con el "gasto de bolsillo». Se muestra de modo estilizado las relaciones entre diversos agentes en las distintas fases del financiamiento, intermediación y gasto (Gráfico 3).

5 Los recursos de la cooperación y las donaciones son, relativamente, bastante limitados en el país por no ser un país considerado en situación de pobreza. En dichos países la cooperación internacional es la principal fuente de financiamiento (OMS, 2000, p. 110. Recuadro 5.1) 
Gráfico 3. Matriz de Flujos: Agentes financiadores, fondos y prestadores en el caso peruano

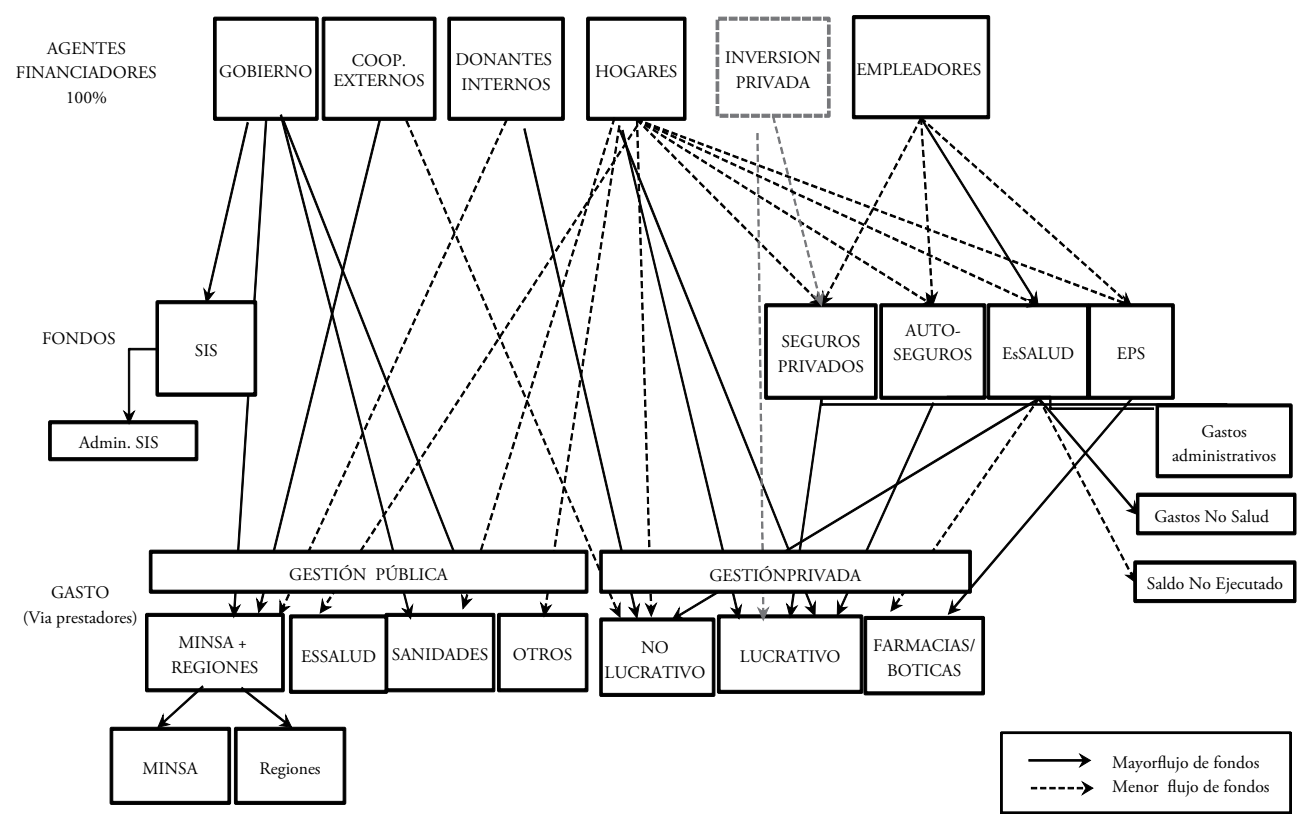

Fuente: Minsa (2015, p. 64).

En el periodo 1995-2012, el gasto en servicios de salud aumentó en $126,8 \%$ en nuevos soles de 2007 en consonancia con el crecimiento económico, siendo su mayor incremento a partir de 2003-2004 en todos los prestadores, incluyendo la compra directa en farmacias/boticas sin pasar previamente por la consulta de un prestador institucional ${ }^{6}$. El gasto realizado dentro de prestadores públicos creció del 2,3\% al 2,8\% del PBI, mientras que el gasto efectuado en establecimientos privados pasó del 2,0\% al 2,3\%. En 2012, el 55\% del gasto se realizaba bajo gestión pública (Minsa, Regiones, EsSalud, Sanidades, Beneficencia, Gobiernos locales) y el $45 \%$ bajo gestión privada (lucrativo, compra directa en farmacia, no lucrativo). Los establecimientos Minsa y Regiones pasaron (2005-2012) a concentrar del 26,3\% al 29,3\% del gasto en salud de ambas, debido a la implementación del proceso de descentralización, cambio drásticamente: Minsa: 13,3\% y Regiones: $16,0 \%$.

\footnotetext{
6 Incluye prestar una receta antigua, y sobre todo la consulta directa sobre síntomas inmediatos al expendedor de medicamentos, que rara vez es el farmacéutico.
} 


\section{4. ¿Quiénes financian la atención de salud en el Perú y cuales SUS DETERMINANTES?}

Perú tiene tres principales agentes financiadores que realizan decisiones que dan origen al gasto en salud: los hogares o economías domésticas que compran servicios de salud afectando su presupuesto familiar; el Gobierno que resuelve asignar mayores o menores recursos vía tesoro público a los presupuestos públicos nacional, regionales y alianzas con el sector privado; y, los empleadores formales que deciden declarar a los trabajadores que se encuentran en planilla o nómina con el consiguiente aporte del $9 \%$ de la remuneración bruta a la seguridad social en salud (EsSalud). Con el crecimiento económico y la consiguiente mejora en los ingresos ha surgido un nuevo agente: el inversor privado, un sujeto muy dinámico, pero sobre el que existe información solo referencial. En el periodo 1995-2012, aunque todos los agentes crecieron en términos absolutos, la participación de los hogares disminuyó de 45,8\% al 37,0\% gracias al incremento del tesoro público a través del Gobierno de 25,2\% al 29,0\%, y al aumento en los aportes de los empleadores de 25,6 al 30,1\%, el que estuvo asociado al crecimiento económico y al ligero aumento en la formalización del empleo (Gráfico 4).

Gráfico 4. Estructura del financiamiento en salud según principales agentes.

Perú 1995-2012

(en \%)

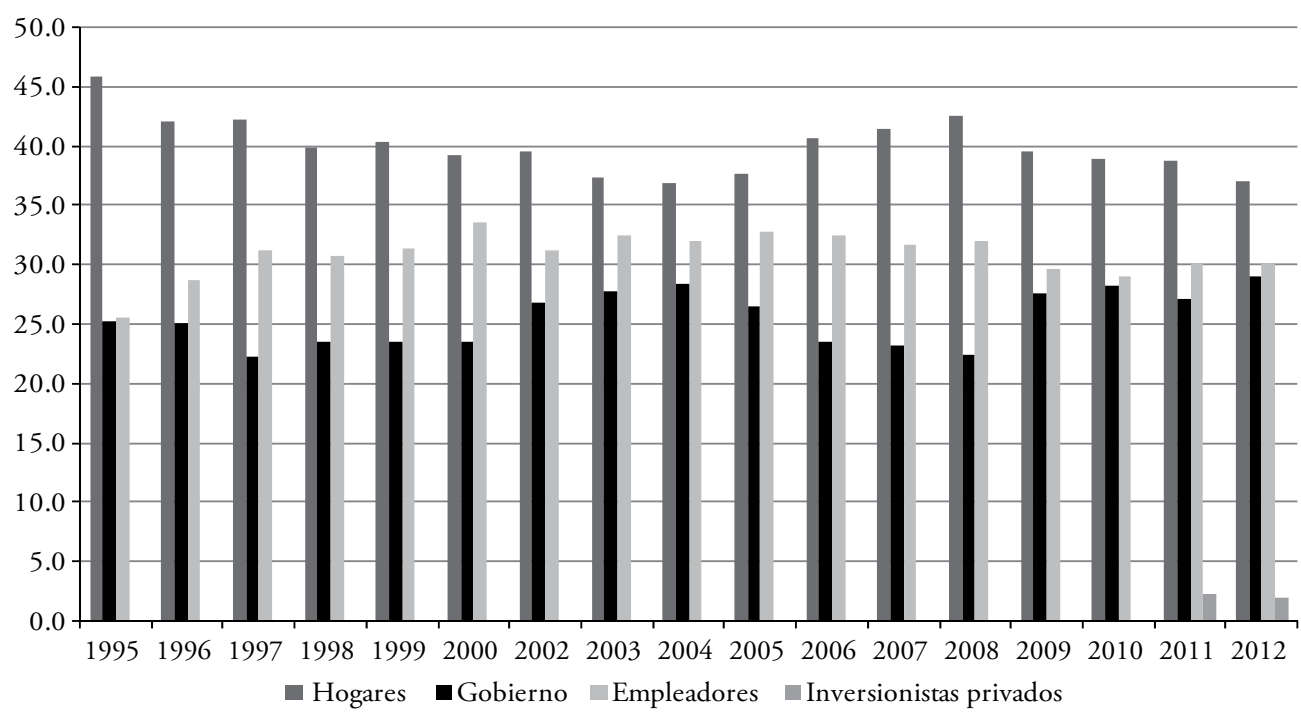

Elaborado sobre la base de Minsa (2015, p. 44). 
Es conocido el rol del crecimiento del PBI en las finanzas públicas, en el gasto de los hogares y en menor medida en la formalización del empleo; todos ellos apuntan a incrementar el gasto en salud. Un determinante adicional e importante es la prioridad relativa asignada no solo por el Ejecutivo, sino también por los Gobiernos regionales a la atención de salud. Se detalla el periodo 2002-2014 para evidenciar el crecimiento de la fuente del tesoro público depurada de acuerdo a la metodología de las CCNNS (Minsa, 2015, pp. 32-35) en los prestadores públicos de salud (Cuadro 2). En dicho periodo el crecimiento fue del $210 \%$ en valores reales (nuevos soles de 2007), sobre todo en el Minsa y Regiones (286\%), y mostró una tendencia ascendente sin precedentes asociada al crecimiento sostenido del PBI. En el actual contexto de menor incremento económico, el escenario será diverso, marcado ya no por la mayor disponibilidad de fondos sino por las prioridades de política nacional.

Cuadro 2. Financiamiento de tesoro público para la función salud depurada (Millones de nuevos soles de 2007)

\begin{tabular}{l|c|c|c|c|c|c|c|c|c|c|c|c|c}
\hline \multicolumn{1}{c|}{ Instituciones } & 2002 & 2003 & 2004 & 2005 & 2006 & 2007 & 2008 & 2009 & $\mathbf{2 0 1 0}$ & $\mathbf{2 0 1 1}$ & $\mathbf{2 0 1 2}$ & $\mathbf{2 0 1 3 / \mathrm { e }}$ & $\mathbf{2 0 1 4 / \mathrm { e }}$ \\
\hline Minsa + Regiones & 2253,8 & 2262,7 & 2530,0 & 2789,1 & 2963,0 & 3340,9 & 3545,1 & 4640,1 & 4862,2 & 5408,2 & 6411,1 & 7659,8 & 8710,2 \\
Minsa & 1554,9 & 1512,2 & 1687,3 & 1811,3 & 1890,4 & 2196,5 & 2182,9 & 2576,5 & 2662,8 & 2839,7 & 3184,4 & 3814,2 & 4452,6 \\
$\begin{array}{l}\text { Regiones } \\
\begin{array}{l}\text { Sanidades, } \\
\text { beneficiencias y } \\
\text { municipios }\end{array}\end{array}$ & 699,0 & 750,5 & 842,7 & 977,8 & 1072,6 & 1144,4 & 1362,2 & 2063,5 & 2199,4 & 2568,6 & 3226,6 & 3845,5 & 4257,6 \\
$\begin{array}{l}\text { Total (millones de } \\
\text { n. soles de 2007) }\end{array}$ & 3139,0 & 3191,5 & 3418,2 & 3241,9 & 3342,7 & 3745,8 & 3988,4 & 5463,8 & 5990,5 & 6206,0 & 7462,7 & 8578,1 & 9728,2 \\
\hline
\end{tabular}

el Estimado

Fuentes: Minsa (2015, p 48). Los años 2013 y 2014 han sido estimados con la misma metodología por la UFEES-OGPP-MINSA.

Profundizar el rol de los hogares en el financiamiento de los servicios de salud ayuda a comprender sus puntos vulnerables. En 2014, el 11,5\% del financiamiento de los hogares se destina a la adquisición de pólizas de seguros mientras que el 88,5\% restante se asigna a la compra directa o "gasto de bolsillo» en servicios de salud. Este tipo de gasto es la forma menos equitativa de asignar los recursos en salud: es regresivo, excluyente, no solidario, no permiten anticipar las ocurrencias de enfermedad/accidente en salud, induce al gasto catastrófico en salud ${ }^{7}$ y afectan sobre todo la salud de los pobres que no pueden pagar los servicios que requieren (OMS, 2012, pp. 47-48). En consecuencia, la OMS ha planteado la conveniencia en reducir la participación del financiamiento de bolsillo hasta no más del 15-20\% del financiamiento total en salud (2012, p. 59) ${ }^{8}$.

\footnotetext{
7 El gasto catastrófico en salud es «aquel gasto derivado de la atención médica que por ser tan elevado para la economía familiar obliga a los individuos o a las familias a reducir significativamente su nivel de vida» (Stiglitz, 1995, p. 338).

8 Para una revisión bibliográfica sobre la validez y comparabilidad del pago de bolsillo en salud proveniente de las encuestas de hogares en los diversos países, ver a nivel mundial a Heijink et al. (2011) y para América Latina a Perticará (2008).
} 
Sobre este gasto de bolsillo de los hogares, conviene efectuar cuatro preguntas sobre dicho gasto: (a) ¿Cuál es el porcentaje del gasto familiar destinado al financiamiento de la atención de su salud?; (b) ¿A quienes compran?; (c) ¿Cuál es el vínculo entre percepción de enfermedad y compra?; (d) ¿Qué servicios compran?

- Si bien el porcentaje del gasto familiar en salud respecto del gasto total aumentó en promedio del 5,0\% (2004) al 5,8\% (2012) en un contexto de crecimiento económico, este aumento fue menor en los más pobres posiblemente por ser los beneficiarios del Seguro Integral de Salud (SIS). Como ha sido señalado por Gakidou et al. (2007) en contextos de crecimiento económico como el peruano, aún con una política exitosa de aseguramiento en salud este tiende a incrementarse, siendo relevante contrastar el crecimiento según quintiles. En Perú, el primer quintil (más pobre) fue el que menos incremento registró: del 3,9\% al $4,1 \%$, mientras que el cuarto y quinto quintil tuvieron aumentos de $5,2 \%$ al $6,3 \%$ y del $6,2 \%$ al $7,8 \%$ respectivamente (Gráfico 5).

Gráfico 5. Gasto de bolsillo en salud según quintiles. Perú 2004-2012 (como \% del gasto familiar)

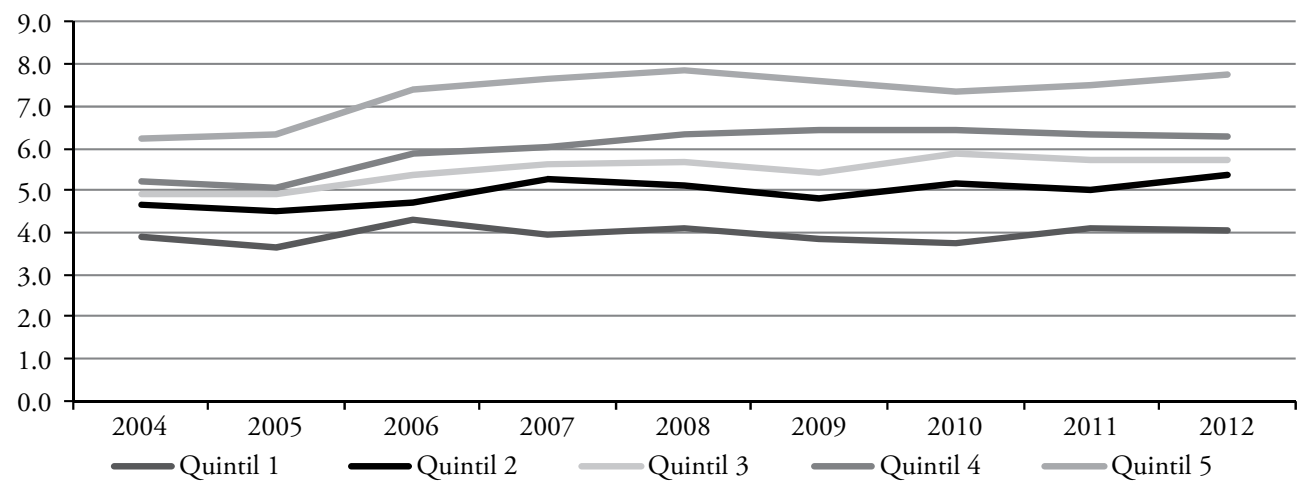

Fuente: Minsa (2015, p. 78).

- El gasto de bolsillo se realiza mayoritariamente en el sector privado, sea al atenderse en prestadores privados ${ }^{9}$, como a través de la compra en farmacias/boticas sin pasar previamente por un prestador formal de servicios de salud ${ }^{10}$. (Gráfico 6). La tendencia al estancamiento en el porcentaje del gasto en la prestación pública respecto del gasto total de los hogares podría estar asociada al incremento en valores absolutos de afiliados al SIS.

\footnotetext{
9 En los últimos años se ha producido la asimilación de farmacias/boticas dentro de establecimientos de prestadores privados.

10 Aunque en Perú está prohibida la venta de muchos medicamentos sin receta médica, esta prohibición no siempre se hace efectiva.
} 
Grafico 6. Destino del financiamiento de los hogares en salud. Perú 2004-2012 (millones de soles de 2007)

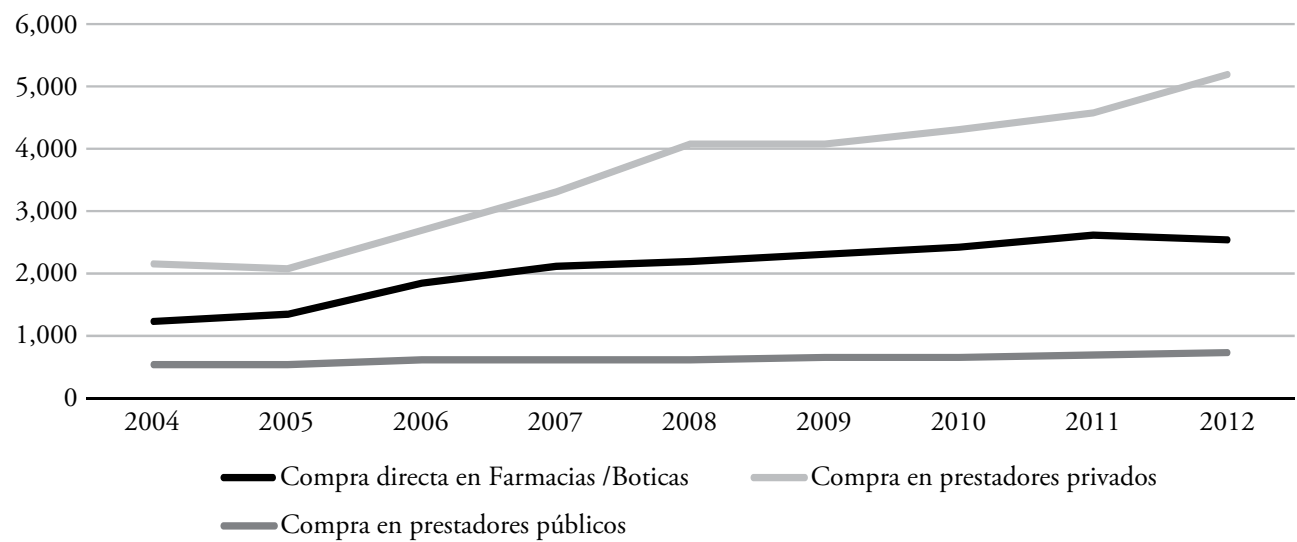

Fuente: Minsa (2015, p. 78).

- Llama la atención el flujo del gasto de los hogares con relación a la percepción de enfermedad y consulta. Una estimación detallada a través de la ruta que recorren los hogares muestra que del $100 \%$ del gasto directo o de bolsillo de los hogares durante 2012 , el $29,9 \%$ no fue efectuado a partir de una consulta: $28,6 \%$ fue realizado a partir de la percepción de enfermedad/accidente, mientras que el $1,3 \%$ restante se hizo, incluso, sin contar con dicha percepción ${ }^{11}$. De otro lado, el $70,1 \%$ del gasto de bolsillo de los hogares fue realizado a partir de una consulta; llama la atención en este subconjunto que el $18,3 \%$ fuera realizado mediante consultas efectuadas directamente en farmacias/boticas, donde el expendedor de medicamentos, más que el farmacéutico a cargo, podría estar cumpliendo el rol de prescriptor para el cual no está calificado. El gasto efectuado a partir de una consulta a un prestador institucional de servicios de salud (Minsa/Regiones, EsSalud, sanidades y consultorios y clínicas privadas) agrupa al 51,8\% del gasto de bolsillo del hogar en salud en dicho año. Dos hechos singulares llaman la atención: (a) del 15,3\% del gasto de los hogares que se origina a partir de una consulta a un establecimiento del Minsa Nacional (Minsa y Regiones) más de la mitad $(9,4 \%)$ se acaba realizado en el sector privado, y (b) el 4,8\% del gasto hecho en el sector privado es efectuado por asegurados a EsSalud que consultaron en sus establecimientos, pero que, presumiblemente por razones de desabastecimiento, tuvieron que adquirir parte de la prescripción en el sector privado, con el consiguiente malestar y efecto en el gasto de bolsillo del asegurado (Gráfico 7).

\footnotetext{
11 Es posible que dicho gasto fuera realizado por personas que saben que tienen una enfermedad crónica que se encuentra asintomática, pero también podría incluir a quienes se convierten en consumidores gracias a la propaganda. Se abre aquí, un sugerente tema de estudio.
} 


\section{Gráfico 7. Flujo del gasto directo de hogares en salud. Perú 2012}

(respecto del 100\% del gasto directo de los hogares)

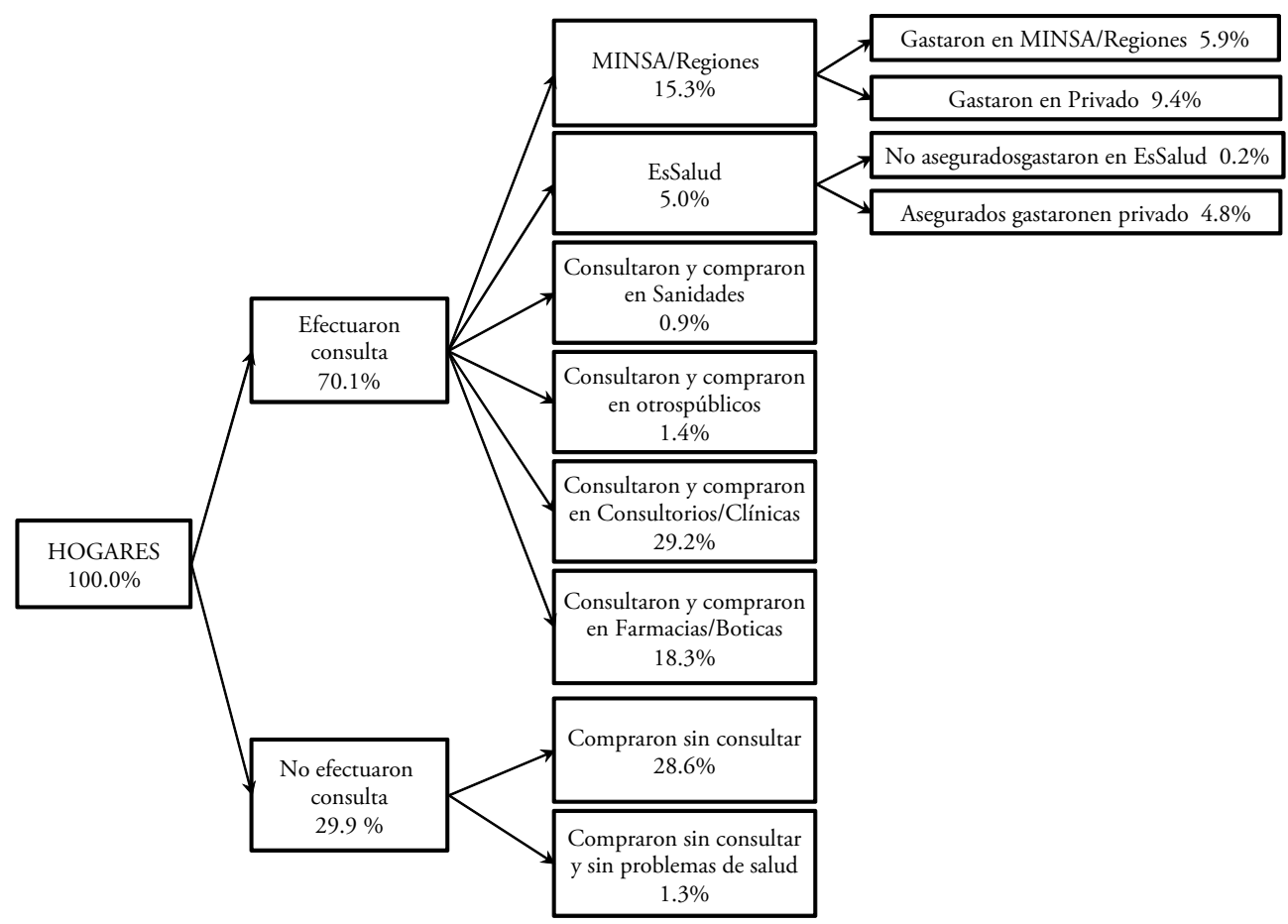

Fuente: Minsa (2015, p. 76).

Dichas observaciones muestran que la consulta en establecimientos públicos tiene el efecto de elevar la demanda en el sector privado, lo que sugiere que dentro del sector público no se completa el circuito de atención de parte de los pacientes, lo que alude a problemas en la capacidad de respuesta del sistema público, la que es tratada en el acápite (6).

¿Qué compran los hogares? Durante el periodo 2004-2012, el principal tipo de gasto en salud de los hogares fueron los medicamentos que absorbieron el 43-47\%. Esta información ha sido consistente con el incremento registrado en el mercado farmacéutico peruano (Minsa, 2015, p. 115). El servicio dental ocupó el segundo puesto y subió de 14,3\% a 15,8\%; seguido de la consulta y hospitalización (7,6\%) (Gráfico 8). 
Gráfico 8. Composición del gasto directo de hogares según el tipo de compra. Perú 2004-2012 (en \%)

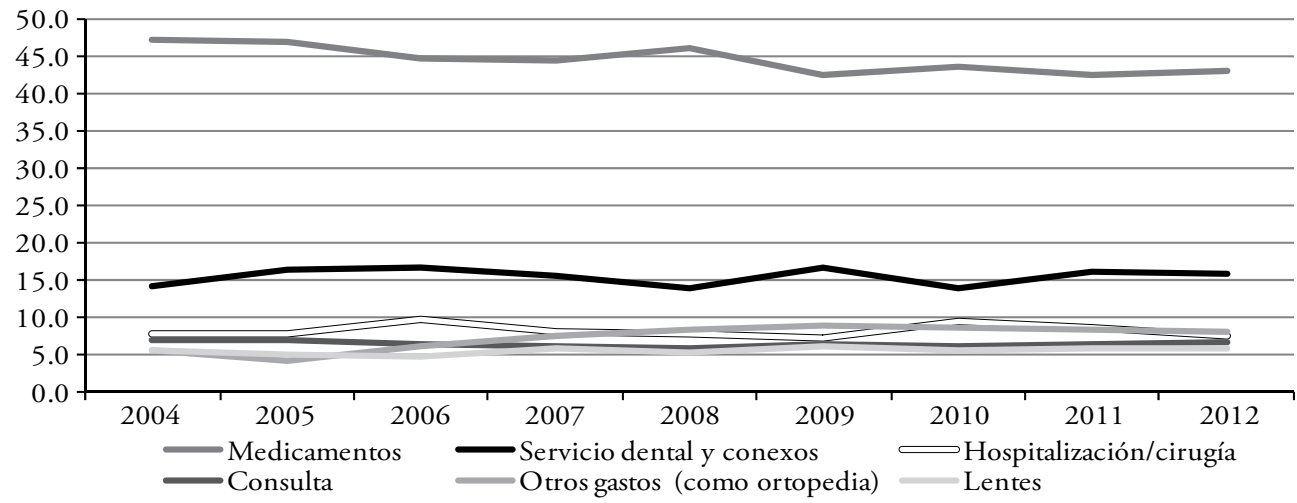

Fuente: Minsa (2015, p. 78).

\subsection{LA INTERMEDIACIÓN DEL FINANCIAMIENTO A TRAVÉS DE FONDOS DE ASEGURAMIENTO}

Entre los ańos 1995-2012 el porcentaje del financiamiento que se intermedió como fondo de aseguramiento creció de 30,7\% a 37,4\%, cambiando drásticamente su estructura con la incorporación del Seguro Integral de Salud (SIS), seguro público destinado mayoritariamente a la población en pobreza y condición de vulnerabilidad y al crecimiento de modalidades privadas: seguros y autoseguros y entidades prestadoras de salud $(\mathrm{EPS})^{12}$ (Gráfico 9).

Gráfico 9. Fondos de salud. Perú 1995-2012

(Millones de nuevos soles de 2007)

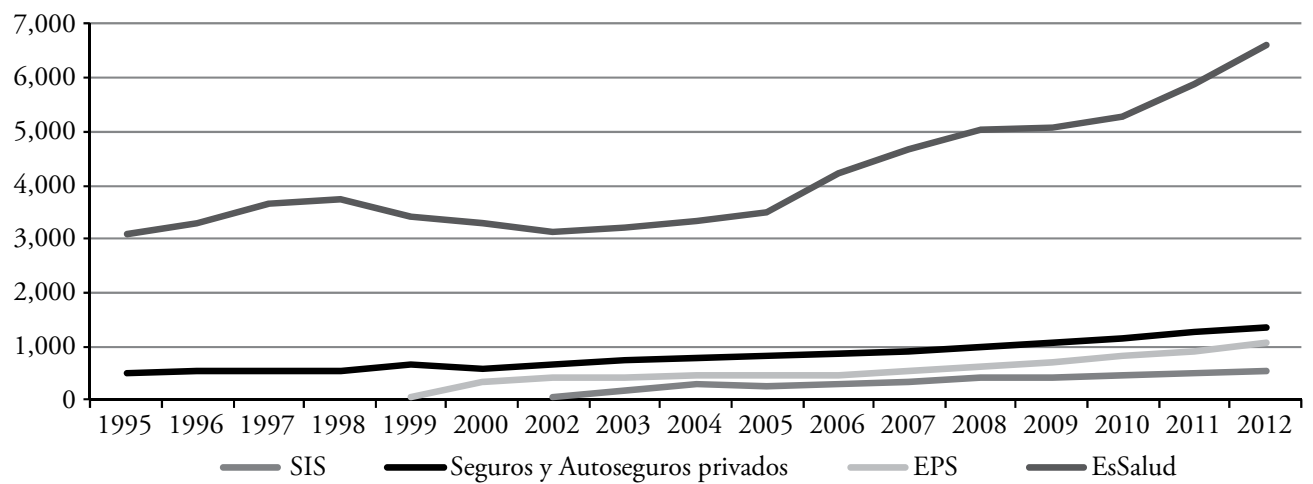

Fuente: Minsa (2015, p. 53).

12 De acuerdo a la ley 26790 de Modernización de la Seguridad Social en Salud, es posible que una cuarta parte del $9 \%$ de la remuneración dirigida a la seguridad social en salud sea canalizada hacia prestadores privados (EPS) debidamente conformados. También canalizan voluntariamente, y en menor medida, cotizaciones a seguros privados de salud. 
Aunque EsSalud sigue siendo el principal fondo de aseguramiento en salud con un fuerte crecimiento desde mediado de la década pasada asociado al crecimiento económico $^{13}$, su participación relativa disminuyó del 85,7\% al 69,0\% del total de recursos financieros intermediados como fondos debido a la incorporación de los nuevos seguros En 2012, las EPS representaron el 11,1\%, los seguros y autoseguros privados el 14,2\% y el SIS el 5,6\%. La evolución de los seguros, autoseguros privados y EPS muestra una tendencia creciente en los ingresos mayor a la de los afiliados (Gráfico 10). No se encuentra disponible el gasto administrativo de EsSalud.

Gráfico 10. Evolución de los seguros privados en afiliados y en millones de soles. Perú 1995-2012(*)

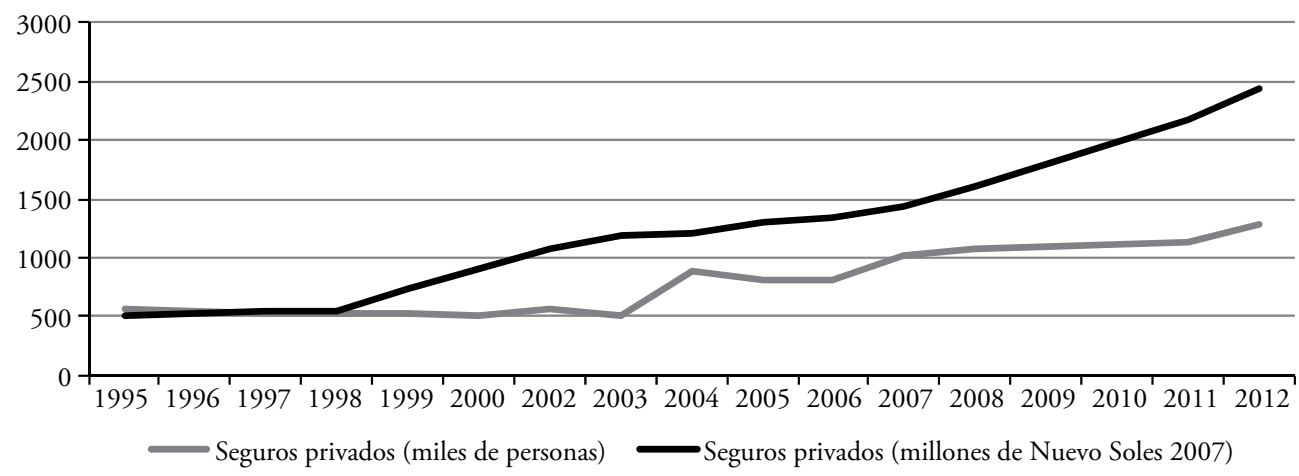

$\left.{ }^{*}\right)$ Incluye a EPS

Elaborado sobre la base de Minsa (2015, pp. 52 y 86).

El peso que el SIS tiene en el total del financiamiento público del Minsa y Regiones ha sido relativamente bajo, aunque va en incremento: del 12,6\% (2002) al 17,0\% (2012). Si bien las atenciones de los afiliados al SIS son costeadas con recursos provenientes del SIS, sobre todo en lo que respecta a insumos y remuneraciones de personal contratado ad hoc, este costo es parcial porque los recursos para la depreciación de infraestructura, equipos y remuneraciones del personal nombrado de los servicios de salud, no pasan por el SIS sino por el presupuesto regular del Minsa y de las Regiones ${ }^{14}$.

13 El 98,0\% de los ingresos que recibió EsSalud en 2012 provinieron de las aportaciones o contribuciones de los asegurados a la seguridad social en salud que declaran y efectúan los empleadores. El $2 \%$ restante fue producto de la venta de servicios de salud a no asegurados, ingresos financieros, ingresos de capital y resultado de ejercicios anteriores autorizados.

${ }^{14}$ Si bien el porcentaje de la población que cuenta con un seguro de salud subió del $24 \%$ al $62 \%$, sobre todo debido al crecimiento en la afiliación al SIS (31,4\% de la población nacional, lo que equivale a 9,7 millones de personas), destinado mayoritariamente a la población en condición de pobreza, no es recomendable comparar el porcentaje crecimiento de los recursos financieros que pasaron a intermediarse con el SIS con el de la personas que transitaron al aseguramiento, ya que la atención por el SIS implica como ya ha sido comentado movilizar también recursos del Minsa y Regiones que no están intermediados por algún fondo. 


\subsection{El SURGIMIENTO DE UNA PARADOJA: PESE AL MAYOR FINANCIAMIENTO PÚBLICO EL CRECIMIENTO DE LA UTILIZACIÓN DE SERVICIOS PÚBLICOS FUE MENOR AL DE LOS PRIVADOS}

Con el crecimiento económico, la utilización de servicios de salud modificó su composición aumentando porcentualmente el uso de prestadores privados. Entre los años 2004-2014 la consulta a los prestadores públicos disminuyó de $25,1 \%$ a 24,4\%, siendo la consulta al Minsa y regiones la de mayor peso disminuyendo de 18,5\% a 17,0\%, habiendo tenido EsSalud el mayor incremento de 5,9\% a 7,0\%. En el mismo periodo, la consulta al sector privado subió de $29,3 \%$ a $38,9 \%$; en los prestadores privados de $4,7 \%$ a $8,7 \%$ y en la farmacia o botica sin consulta previa a prestador institucional de servicios de salud de $24,6 \%$ a 29,8\% (Cuadro 3 y Gráfico 11).

Entre los años 2004-2012 aunque en números absolutos aumentaron los usuarios de servicios de salud del Minsa y Regiones (de 2,6 a 3,0 millones de personas), tuvo una disminución porcentual (de 18,5 a 16,1\%) en comparación con el importante esfuerzo fiscal (tesoro público) realizado que aumentó en $244 \%$ en valores reales (Cuadro 2). ¿Qué otros hechos ocurrieron para dificultar la prestación de servicios de salud del Minsa y Regiones?

Cuadro 3. Utilización de servicios de salud. Perú. 2004, 2010, 2014

(Del 100\% de la población que autorreportó enfermedad o malestar en las últimas 4 semanas)

\begin{tabular}{l|r|r|r}
\hline \multicolumn{1}{c|}{ Prestador de salud } & $\mathbf{2 0 0 4}$ & $\mathbf{2 0 1 2}$ & $\mathbf{2 0 1 4}$ \\
\hline Minsa y Regiones (\%) & 18,5 & 16,1 & 17,0 \\
Consulta Minsa (millones de personas) & 2,6 & 3,0 & 3,2 \\
EsSalud (\%) & 5,9 & 6,6 & 7,0 \\
Sanidades (\%) $\left(^{*}\right)$ & 0,7 & 0,6 & 0,4 \\
Consultorio/Clinica Privada (\%) & 4,7 & 9,1 & 8,7 \\
Farmacia o botica (\%) & 24,6 & 29,3 & 29,8 \\
Metodos tradicionales (\%) $\left(^{*}\right)$ & 1,1 & 1,1 & 0,5 \\
Consulta en mas de uno (\%) $\left(^{*}\right)$ & 0,2 & 0,3 & 0,3 \\
No consulta (\%) & 41,7 & 36,9 & 35,2 \\
Total personas con autoreporte problemas en salud (\%) & 100,0 & 100,0 & 100,0 \\
Total personas con autoreporte (millones) & 14,1 & 18,5 & 18,6 \\
\hline
\end{tabular}

$\left(^{*}\right)$ Referencial

Fuente: Minsa (2015, p. 93; 2014 actualización propia). 
Gráfico 11. Utilización de servicios de salud según prestadores. Perú 2004-2014 (en $\%$ de personas que acuden del $100 \%$ que percibe molestia en salud)

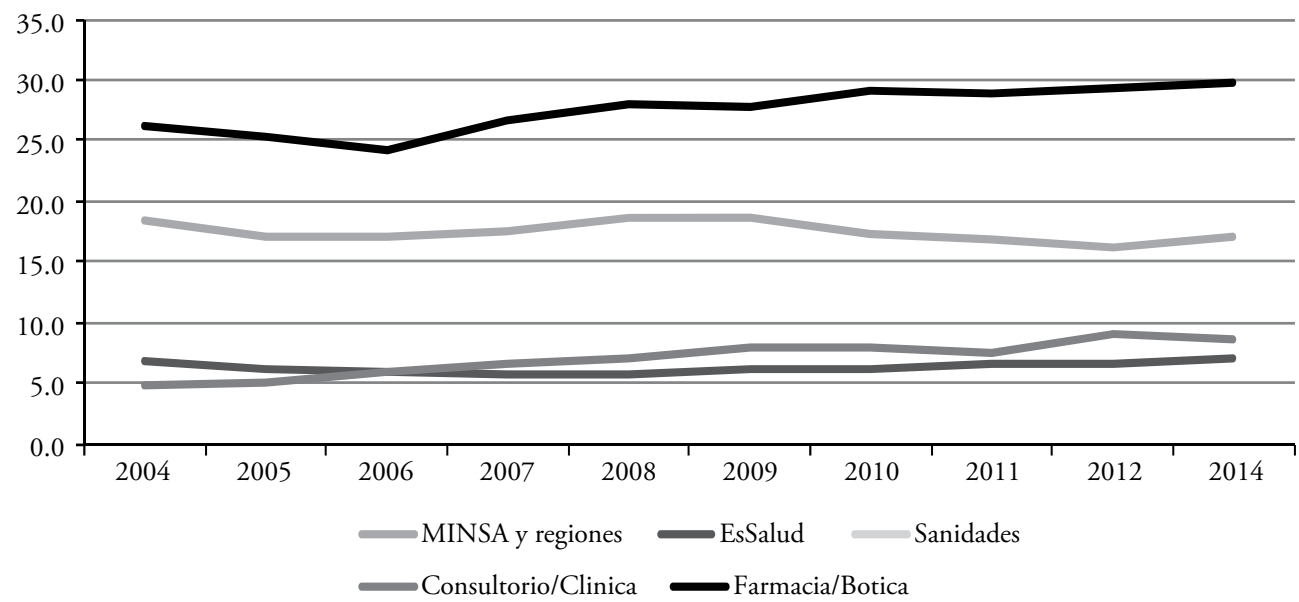

Elaborado sobre la base de Minsa (2015, p. 93 y actualización propia).

Se pueden detectar algunos problemas que podrían haber mermado la falta de capacidad de respuesta del sistema: (a) mecanismos de contención en prestadores debido a la fuerte presión por la demanda debida al gran incremento de afiliados al SIS que pasó de 4,1 a 9,7 millones (2004-2012); (b) escasez de recursos humanos, reticencia (pese a incentivos) a ir fuera de grandes ciudades y prolongadas huelgas del personal de salud, sobre todo de médicos, que se dieron y continuaron en los años 2013 y 2014 lo que paralizó la prestación de servicios de salud del Minsa Regiones y de EsSalud; (c) la estructura de gasto del Minsa y regiones sufrió importantes cambios desde el año 2008 en adelante dando importancia a las inversiones ${ }^{15}$. (Cuadro 4). A diferencia de otros gastos, el de inversiones, no se usufructúa en el presente, más aún con su lenta ejecución y las dificultades de coordinación entre el gasto de inversión y el gasto corriente que caracterizan a la inversión pública; (d) Fallas en la articulación entre sistemas administrativos (planeamiento presupuesto, contabilidad y logística); $y$, (e) una limitada coordinación y rectoría entre el Minsa y Regiones al amparo de una descentralización inconclusa.

15 Particularmente en el Minsa, estas tuvieron su mayor participación en 2011 y 2012, para luego declinar a favor de la participación de las remuneraciones debido a la política de nombramientos. En las Regiones las inversiones continuaron su alza hasta 2013 para luego declinar ligeramente en 2014 
Cuadro 4. Estructura del gasto ejecutado en salud del Minsa y Regiones según genéricas de gasto. Perú

(\%)

\begin{tabular}{|c|c|c|c|c|c|c|c|c|c|c|}
\hline MINSA & 2005 & 2006 & 2007 & 2008 & 2009 & 2010 & 2011 & \multicolumn{3}{|c|}{2012 2013/e 2014/e } \\
\hline Personal $\left(^{*}\right)$ & 60,5 & 62,0 & 56,4 & 58,4 & 46,9 & 47,4 & 48,8 & 48,5 & 50,0 & 54,4 \\
\hline Otras prestaciones sociales $\left({ }^{* *}\right)$ & 0,0 & 0,0 & 0,0 & 0,0 & 1,8 & 1,0 & 0,2 & 0,3 & 0,2 & 0,1 \\
\hline Bienes y servicios $\left({ }^{* * *}\right)$ & 31,0 & 31,2 & 33,5 & 32,4 & 36,1 & 34,9 & 31,9 & 35,0 & 32,8 & 32,6 \\
\hline Donaciones y transferencias & 0,0 & 0,0 & 0,0 & 0,0 & 0,0 & 0,0 & 0,1 & 0,0 & 0,1 & 0,1 \\
\hline Otros gastos corrientes & 0,1 & 0,2 & 0,1 & 0,0 & 1,6 & 2,6 & 1,5 & 2,1 & 6,0 & 3,7 \\
\hline Inversión & 8,4 & 6,6 & 10,1 & 0,0 & 13,6 & 14,1 & 17,5 & 14,0 & 11,0 & 9,1 \\
\hline TOTAL MINSA & 100,0 & 100,0 & 100,0 & 100,0 & 100,0 & 100,0 & 100,0 & 100,0 & 100,0 & 100,0 \\
\hline REGIONES & 2005 & 2006 & 2007 & 2008 & 2009 & 2010 & 2011 & 2012 & 2013 & 2014 \\
\hline Personal $\left(^{*}\right)$ & 70,8 & 70,3 & 67,9 & 68,3 & 57,5 & 60,8 & 59,6 & 57,9 & 52,8 & 60,0 \\
\hline Otras prestaciones sociales $\left({ }^{* *}\right)$ & 0,0 & 0,0 & 0,0 & 0,0 & 0,0 & 0,1 & 0,1 & 0,2 & 0,1 & 0,1 \\
\hline Bienes y servicios $\left({ }^{* * *}\right)$ & 25,9 & 25,1 & 24,2 & 27,2 & 22,4 & 23,5 & 22,8 & 21,9 & 18,6 & 18,8 \\
\hline Otros gastos corrientes & 0,9 & 0,9 & 0,8 & 0,6 & 1,3 & 1,4 & 3,5 & 1,0 & 4,5 & 2,1 \\
\hline Inversión & 2,4 & 3,7 & 7,1 & 3,9 & 18,7 & 14,2 & 14,1 & 19,1 & 24,1 & 19,0 \\
\hline TOTAL REGIONES & 100,0 & 100,0 & 100,0 & 100,0 & 100,0 & 100,0 & 100,0 & 100,0 & 100,0 & 100,0 \\
\hline
\end{tabular}

e/ Preeliminar

$\left(^{*}\right)$ Agrupa el gasto por contratos CAS y Servicios no personales al gasto de Personal y obligaciones sociales

${ }^{(*)}$ Servicios gratuitos vinculadas a la salud de brigadas y actividades de capacitación/mantenimiento

(***) A Bienes y Servicios se le sustrae el gasto por contratos CAS y Servicios no personales

Fuentes: Minsa (2015, p. 48). Ańos 2013 y 2014 estimados con la misma metodología por la UFEES-OGPP-MINSA.

\subsection{UNIVERSALIZACIÓN DEL ASEGURAMIENTO EN SALUD, ACCESO Y GASTO DE BOLSILLO}

La universalización del aseguramiento en salud es una estrategia para avanzar hacia el acceso universal (Minsa, 2013, Cap. 2). De acuerdo a declaraciones de los hogares (ENAHO-INEI) el aseguramiento en salud subió de 24,4\% (1995) a 61,8\% (2014) de la población nacional liderado por el SIS: 56,7\% del total de afiliados a un seguro de salud, estaba afiliado a él (2014). El SIS está enfocado mayoritariamente en la población en pobreza y vulnerabilidad, lo que generó un incremento importante en la demanda, que no pudo ser totalmente resuelto por la mayor oferta pública en la atención y gratuidad esperada.

Si bien el estudio demuestra (2012) que mientras que existe un grado de filtración de parte de los quintiles de mayor ingreso (cuarto y quinto) que llega al 13,9\% del total de afiliados al SIS y todavía estaban pendientes de afiliación el 28,8\% de la población del primer quintil y el 42,0\% del segundo quintil (Minsa, 2015, pp. 88, 91) -lo que sin duda es un reto pendiente-, el principal problema es el de acceso; es decir de insuficiente capacidad de respuesta de la oferta y del sistema en su conjunto ante un crecimiento sin precedentes en la demanda. 
Dos hechos son resaltados ${ }^{16}$. Primero, comparando al interior de la población en pobreza relativa aquella afiliada al SIS de la no afiliada, se observa un efecto positivo de protección contra el riesgo financiero que se traduce en un mayor acceso de la población en pobreza relativa afiliada al SIS de aquella no afiliada (Cuadro 5), así como en un menor gasto realizado en afiliados SIS versus no afiliados (Minsa, 2015, pp. 79, 82) (Gráficos 12a y 12b).

Grafico 12a. Gasto personal promedio de bolsillo en población en pobreza urbana según afiliación al SIS en Minsa y Regiones. Perú 2004-2014 (nuevos soles 2014)

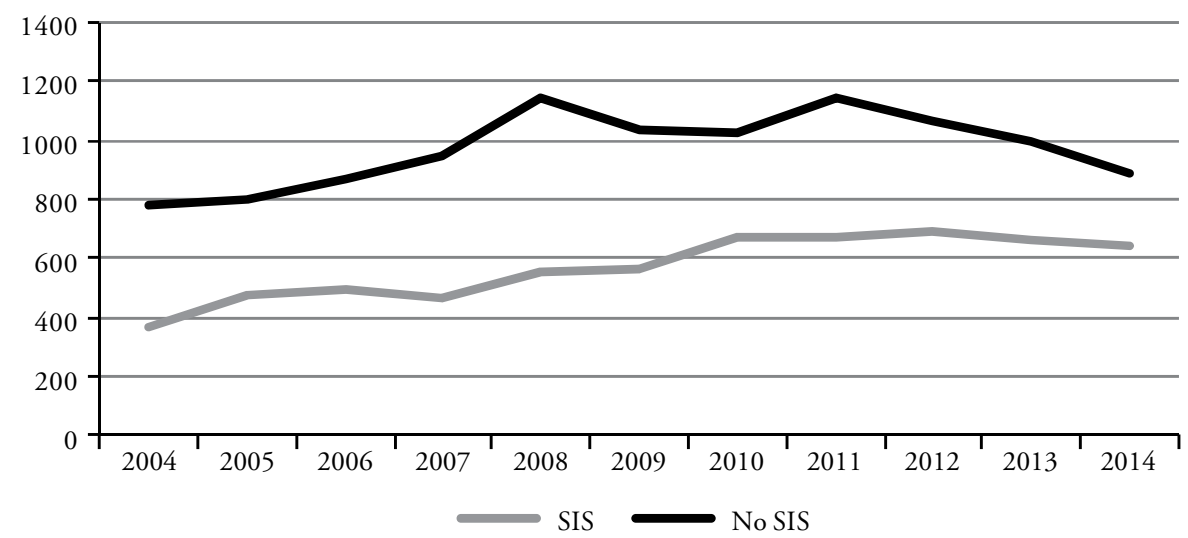

Fuente: Minsa (2015, p. 82).

Gráfico 12b. Gasto personal promedio de bolsillo en población en pobreza rural según afiliación al SIS en Minsa y Regiones. Perú 2004-2014 (nuevos soles 2014)

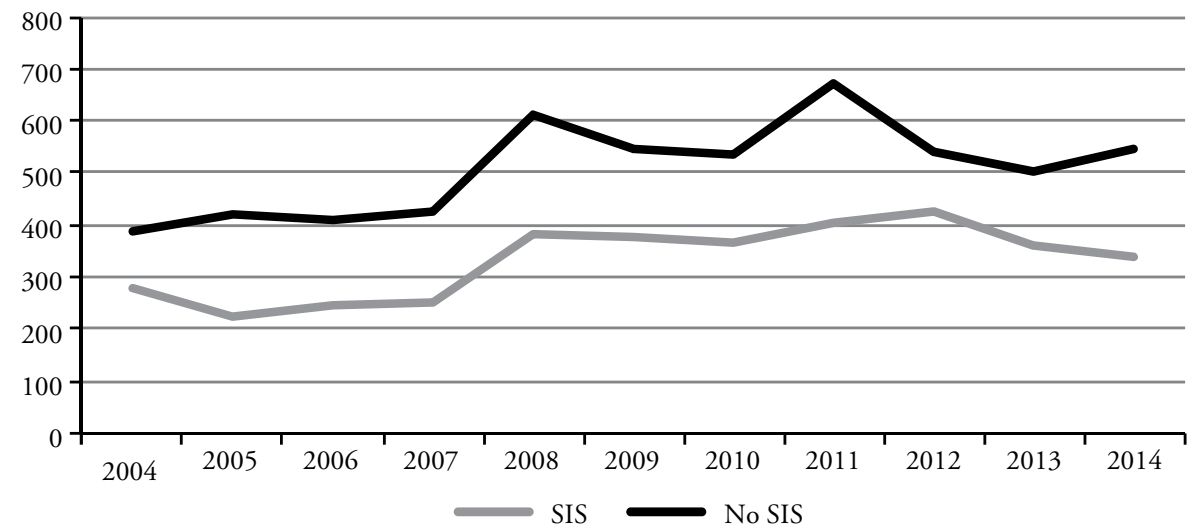

Fuente: Minsa (2015, p. 82).

16 Ya reportado en Petrera (2012, pp. 71-72). 
Segundo, si bien el SIS logró un mayor acceso de sus afiliados en términos absolutos, no ha podido garantizar la atención de la gran mayoría de sus afiliados a los servicios de salud de la red nacional del Minsa. Así en el periodo (2004-2012) del 100\% de la población que autorreportó problemas de salud, el porcentaje de afiliados al SIS que acudió a establecimientos del Minsa y Regiones disminuyó de 56,0\% a 37,5\%, lo que reveló severos problemas en su oferta (Minsa, 1995, pp. 103-104).

Esta limitada correspondencia entre contar con un seguro y poder usufructuar sus beneficios cuando el afiliado se autopercibe con problemas de salud, ocurre también con otros seguros o fondos de salud. En el mismo periodo de estudio, si bien los afiliados a EsSalud que acudieron a sus establecimientos aumentaron en $29,5 \%$, en números absolutos disminuyeron porcentualmente de $38,7 \%$ a $28,0 \%$ y duplicaron su consulta en consultorios y clínicas privadas ${ }^{17}$. El caso de los asegurados a las sanidades de las Fuerzas Armadas y Policía Nacional, parece $\operatorname{ser}^{18}$ más dramático porque no se registra un aumento de atendidos en sus establecimientos ${ }^{19}$ mientras que el decrecimiento porcentual fue mayor de $41,7 \%$ a 27,8\%. En consecuencia, en todos estos seguros (SIS, EsSalud y Sanidades) la consulta en farmacias y boticas se incrementó considerablemente, pero también aumentó la no consulta. Solo en quienes contaron con seguro privado que pertenecen generalmente a los estratos de mayores ingresos, se sugiere un aumento en la consulta a consultorios y clínicas tanto en valores absolutos como porcentuales y una menor consulta en farmacias ${ }^{20}$ (Cuadro 5).

Se observa la menor asistencia en términos absolutos y porcentuales de la población que acudió al Minsa y Regiones sin contar con un seguro de salud; esta disminuyó de 1,4 a 0,8 millones de personas y porcentualmente de $21,5 \%$ a $13,7 \%$, lo que abona la existencia de un efecto de sustitución entre los usuarios del Minsa y Regiones: al aumentar el número de afiliados al SIS, disminuye el de las personas que no cuentan con un seguro de salud reforzándose la hipótesis de restricción de la oferta del Minsa y Regiones, así como la insatisfacción en sus prestadores ante la menor liquidez (ver Petrera, 2012, pp. $65-67)^{21}$.

\footnotetext{
${ }^{17}$ No obstante, debe considerarse que, para muchos asegurados a EsSalud, este seguro sea más valorado cuando se trate de enfermedades y cirugías de mayor complejidad y costo.

18 Dado el limitado tamańo de asegurados a las sanidades, como a los seguros privados, se sugiere que las cifras sean referenciales.

19 Más bien se sugiere un decrecimiento de 83 a 82,6 miles de personas (Cuadro 5).

20 El caso de quienes tienen, además de EsSalud, un seguro privado es también referencial y sugiere alta preferencia por la prestación privada. No obstante, no es posible inferir el comportamiento ante enfermedades y cirugías de alto costo.

21 Desde 2012 y masificado a todo el país en 2014, el SIS ha generalizado el cambio en los mecanismos de pago introduciendo modalidades de pago per cápita y pago adelantado para parte de los servicios. Se espera que estos cambios induzcan a una mayor atención a los afiliados al SIS de parte de los prestadores del Minsa y Regiones.
} 


\section{Cuadro 5}

Utilización de servicios de salud según tipo de seguro. Perú 2004, 2012

(Del total de la población que autorreportó enfermedad o malestar en salud)

\begin{tabular}{|c|c|c|c|c|c|c|c|c|c|}
\hline \multirow[b]{2}{*}{ Año } & \multirow[b]{2}{*}{ Tipo de seguro } & \multicolumn{5}{|c|}{ ¿Donde consultó ? } & \multicolumn{2}{|c|}{ No consultó porque... } & \multirow[b]{2}{*}{ Total } \\
\hline & & $\begin{array}{l}\text { Minsa y } \\
\text { Regiones }\end{array}$ & EsSalud & Sanidades & \begin{tabular}{|c} 
Consultorio \\
/Clínica
\end{tabular} & $\begin{array}{c}\text { Farmacia/ } \\
\text { Botica }\end{array}$ & $\begin{array}{c}\text { No } \\
\text { necesito }\end{array}$ & $\begin{array}{l}\text { No } \\
\text { pudo }\end{array}$ & \\
\hline \multicolumn{10}{|c|}{ En miles de personas } \\
\hline \multirow{6}{*}{2004} & EsSalud & 187,9 & 907,5 & 0,4 & 134,3 & 600,7 & 356,8 & 106,3 & 2342,3 \\
\hline & EsSalud y privado & 7,8 & 8,2 & 0,1 & 41,3 & 17,3 & 18,7 & 1,8 & 101,2 \\
\hline & Privado & 7,1 & 2,1 & 0,1 & 42,0 & 29,1 & 31,1 & 1,6 & 113,7 \\
\hline & Sanidades & 9,2 & 0,3 & 83,0 & 14,0 & 47,5 & 35,0 & 6,5 & 198,9 \\
\hline & SIS & 1015,1 & 7,1 & 0,0 & 33,8 & 366,1 & 321,1 & 53,2 & 1812,8 \\
\hline & No asegurado & 1356,2 & 27,1 & 2,3 & 385,9 & 2594,7 & 1512,2 & 323,0 & 6312,2 \\
\hline \multirow{6}{*}{2012} & EsSalud & 250,1 & 1175,1 & 3,6 & 445,7 & 1223,8 & 762,8 & 200,2 & 4189,7 \\
\hline & EsSalud y privado & 6,4 & 21,3 & 0,0 & 113,0 & 52,8 & 53,1 & 9,7 & 264,5 \\
\hline & Privado & 6,4 & 0,9 & 1,0 & 94,1 & 42,2 & 51,6 & 8,9 & 212,6 \\
\hline & Sanidades & 25,0 & 3,4 & 82,6 & 32,6 & 83,0 & 58,9 & 8,2 & 297,4 \\
\hline & SIS & 1892,9 & 8,3 & 1,2 & 236,5 & 1424,4 & 1063,8 & 366,1 & 5056,2 \\
\hline & No asegurado & 794,4 & 7,9 & 4,2 & 726,9 & 2492,6 & 1298,4 & 387,3 & 5796,7 \\
\hline \multicolumn{10}{|c|}{ En porcentajes $(*)$} \\
\hline \multirow{6}{*}{2004} & EsSalud & 8,0 & 38,7 & 0,0 & 5,7 & 25,6 & 15,2 & 4,5 & 97,9 \\
\hline & EsSalud y privado & 7,7 & 8,1 & 0,1 & 40,9 & 17,1 & 18,5 & 1,8 & 94,2 \\
\hline & Privado & 6,3 & 1,9 & 0,1 & 36,9 & 25,6 & 27,4 & 1,4 & 99,5 \\
\hline & Sanidades & 4,6 & 0,1 & 41,7 & 7,0 & 23,9 & 17,6 & 3,2 & 98,3 \\
\hline & SIS & 56,0 & 0,4 & 0,0 & 1,9 & 20,2 & 17,7 & 2,9 & 99,1 \\
\hline & No asegurado & 21,5 & 0,4 & 0,0 & 6,1 & 41,1 & 24,0 & 5,1 & 98,2 \\
\hline \multirow{6}{*}{2012} & EsSalud & 6,0 & 28,0 & 0,1 & 10,6 & 29,2 & 18,2 & 4,8 & 96,9 \\
\hline & EsSalud y privado & 2,4 & 8,1 & 0,0 & 42,7 & 20,0 & 20,1 & 3,7 & 96,9 \\
\hline & Privado & 3,0 & 0,4 & 0,5 & 44,2 & 19,9 & 24,2 & 4,2 & 96,5 \\
\hline & Sanidades & 8,4 & 1,1 & 27,8 & 11,0 & 27,9 & 19,8 & 2,8 & 98,8 \\
\hline & SIS & 37,4 & 0,2 & 0,0 & 4,7 & 28,2 & 21,0 & 7,2 & 98,8 \\
\hline & No asegurado & 13,7 & 0,1 & 0,1 & 12,5 & 43,0 & 22,4 & 6,7 & 98,5 \\
\hline
\end{tabular}

(*) Los totales son menores al $100 \%$ por cuanto se omiten las columnas «más de una vez» $\mathrm{y}$ «consulta tradicional» debido a su limitado tamaño.

Fuente: Minsa (2015, p. 103) y base de datos del estudio.

Una exploración de los motivos de no acceso percibidos por las personas en el periodo 2004-2014 discriminando según afiliación al SIS al interior de la población en pobreza relativa (primer y segundo quintil), permite observar que el uso de remedios caseros y la autoprescripción ocupa el primer lugar en ambos ámbitos con muy escasas diferencias entre contar con el SIS o no tener seguro. La «Falta de tiempo», motivo más urbano 
que rural, se ha incrementado a lo largo del periodo, lo que se presta a un estudio específico $^{22}$. El efecto del SIS parece centrarse en disminuir el peso de la «Falta de dinero» de parte de los afiliados al SIS en ambos medios; no obstante, este efecto tiende a acortarse en el tiempo (Gráfico 13); (b) De otro lado, las causas "Maltrato», «Falta de confianza» $\mathrm{y}$ «Demora en atender» asociadas a problemas en la disponibilidad de la oferta, van elevando su peso tanto en afiliados como en no afiliados al SIS sobre todo en el ámbito urbano (Cuadro 6).

Gráfico 13a. Falta de dinero como motivo de no acceso en población urbana en pobreza relativa. Perú 2005-2014

(\% de personas)

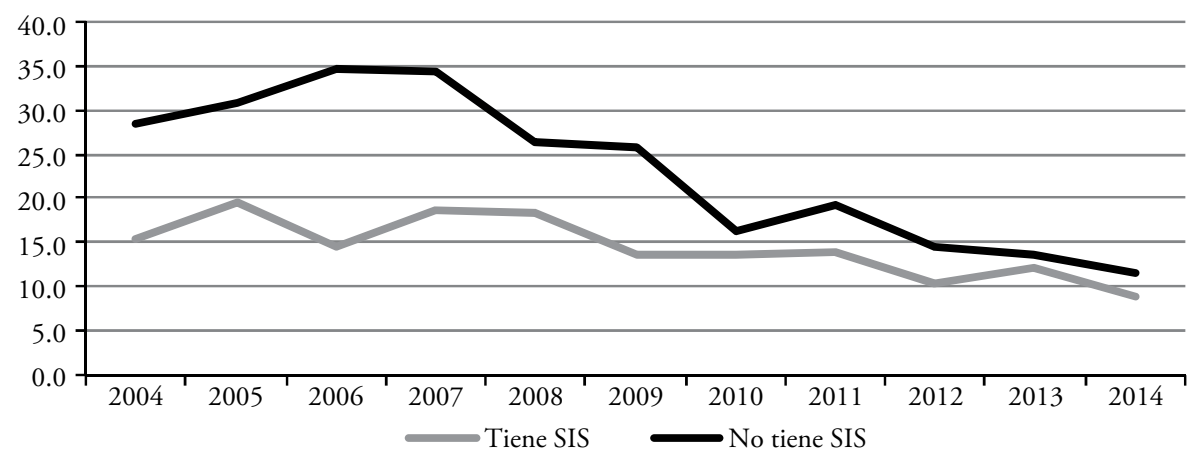

Fuente: Cuadro 6.

Cuadro 13b. Falta de dinero como motivo de no acceso en población rural en pobreza relativa. Perú 2004-2015

(\% de personas)

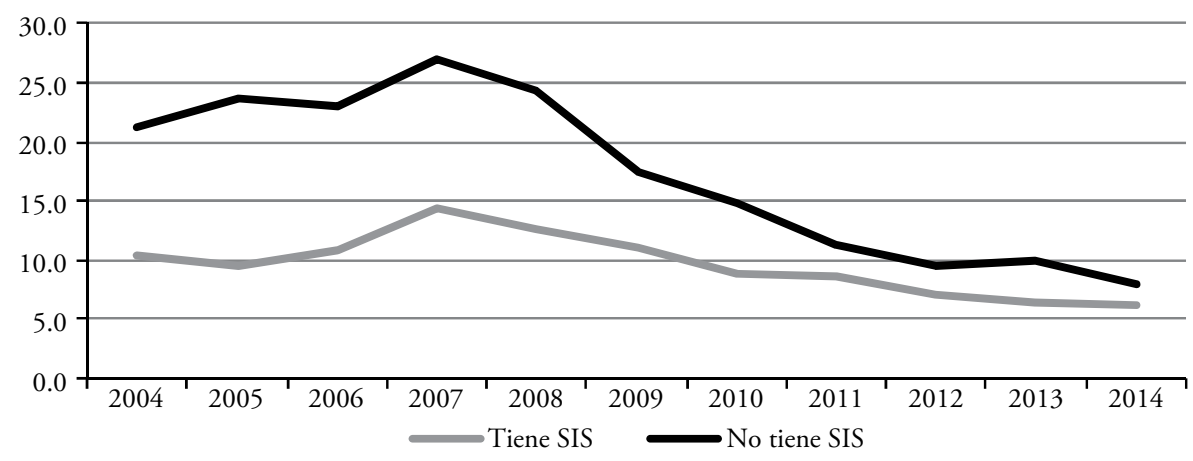

Fuente: Cuadro 6.

\footnotetext{
22 Podría sugerir diversas causas y sus combinaciones, tales como que la atención de la salud podría competir con otras prioridades que las personas o el hogar consideren, además de la existencia de costos no monetarios de acceso, como largas listas de espera, entre otras.
} 
Cuadro 6. Motivos de no atención en población en pobreza relativa afiliada y no afiliada al SIS. Perú 2004-2014

(Porcentajes con relación al 100\% que declara autopercepción de problemas de salud)

\begin{tabular}{|c|c|c|c|c|c|c|c|c|c|c|}
\hline & & $\begin{array}{c}\text { Falta de } \\
\text { dinero }\end{array}$ & $\begin{array}{c}\text { Maltrato, falta } \\
\text { de confianza, } \\
\text { demoran en } \\
\text { atender }\end{array}$ & $\begin{array}{c}\text { Remedios } \\
\text { caseros, } \\
\text { autorreceta }\end{array}$ & $\begin{array}{c}\text { Falta de } \\
\text { tiempo }\end{array}$ & $\begin{array}{c}\text { Distan- } \\
\text { cia }\end{array}$ & $\begin{array}{c}\text { No tiene } \\
\text { seguro }\end{array}$ & Otros & $\begin{array}{l}\text { Otras } \\
\text { combina- } \\
\text { ciones }\end{array}$ & Total \\
\hline \multicolumn{11}{|c|}{ Urbana } \\
\hline \multirow{2}{*}{2004} & SIS & 15,5 & 6,0 & 34,8 & 9,0 & 0,6 & 0,0 & 1,3 & 32,9 & 100,0 \\
\hline & NO SIS & 28,5 & 5,0 & 28,4 & 4,3 & 0,4 & 0,6 & 0,6 & 32,1 & 100,0 \\
\hline \multirow{2}{*}{2005} & SIS & 19,5 & 5,5 & 33,2 & 10,8 & 0,8 & 0,0 & 2,2 & 28,0 & 100,0 \\
\hline & NO SIS & 31,0 & 6,1 & 25,7 & 5,7 & 0,6 & 1,7 & 0,7 & 28,4 & 100,0 \\
\hline \multirow{2}{*}{2006} & SIS & 14,5 & 4,9 & 46,5 & 8,0 & 0,2 & 0,0 & 3,4 & 22,4 & 100,0 \\
\hline & NO SIS & 34,8 & 5,8 & 26,2 & 6,7 & 0,3 & 1,5 & 0,9 & 23,8 & 100,0 \\
\hline \multirow{2}{*}{2007} & SIS & 18,6 & 8,1 & 32,1 & 12,0 & 0,7 & 0,0 & 4,6 & 23,9 & 100,0 \\
\hline & NO SIS & 34,5 & 5,7 & 22,9 & 8,4 & 0,8 & 1,4 & 1,5 & 24,7 & 100,0 \\
\hline \multirow{2}{*}{2008} & SIS & 18,5 & 9,0 & 25,8 & 12,7 & 0,6 & 0,0 & 5,6 & 27,7 & 100,0 \\
\hline & NO SIS & 26,3 & 6,3 & 21,6 & 10,5 & 0,7 & 1,7 & 1,9 & 30,8 & 100,0 \\
\hline \multirow{2}{*}{2009} & SIS & 13,6 & 10,5 & 23,3 & 14,2 & 1,0 & 0,0 & 5,5 & 32,0 & 100,0 \\
\hline & NO SIS & 25,9 & 7,2 & 18,8 & 11,3 & 0,6 & 2,2 & 2,3 & 31,6 & 100,0 \\
\hline \multirow{2}{*}{2010} & SIS & 13,5 & 11,4 & 20,3 & 13,7 & 1,6 & 0,0 & 6,3 & 33,2 & 100,0 \\
\hline & NO SIS & 16,2 & 15,2 & 16,0 & 14,5 & 0,8 & 2,3 & 3,1 & 32,0 & 100,0 \\
\hline \multirow{2}{*}{2011} & SIS & 14,0 & 11,4 & 16,7 & 13,9 & 1,3 & 0,0 & 6,8 & 35,9 & 100,0 \\
\hline & NO SIS & 19,1 & 8,6 & 17,6 & 11,6 & 0,8 & 4,3 & 2,5 & 35,5 & 100,0 \\
\hline \multirow{2}{*}{2012} & SIS & 10,5 & 11,6 & 20,5 & 14,0 & 1,0 & 0,0 & 6,3 & 36,3 & 100,0 \\
\hline & NO SIS & 14,4 & 9,0 & 19,2 & 11,2 & 0,6 & 3,6 & 2,8 & 39,0 & 100,0 \\
\hline \multirow{2}{*}{2013} & SIS & 12,0 & 13,5 & 23,3 & 13,0 & 1,1 & 0,0 & 5,0 & 32,2 & 100,0 \\
\hline & NO SIS & 13,5 & 8,4 & 20,4 & 13,0 & 1,0 & 3,4 & 2,4 & 37,9 & 100,0 \\
\hline \multirow{2}{*}{2014} & SIS & 8,9 & 12,0 & 21,6 & 12,4 & 1,3 & 0,0 & 4,7 & 39,1 & 100,0 \\
\hline & NO SIS & 11,4 & 9,7 & 23,1 & 11,6 & 0,9 & 4,3 & 2,3 & 36,6 & 100,0 \\
\hline \multicolumn{11}{|c|}{ Rural } \\
\hline \multirow{2}{*}{2004} & SIS & 10,4 & 4,8 & 25,3 & 4,1 & 9,0 & 0,0 & 2,4 & 44,0 & 100,0 \\
\hline & NO SIS & 21,2 & 4,4 & 22,3 & 3,0 & 5,6 & 0,8 & 0,8 & 42,0 & 100,0 \\
\hline \multirow{2}{*}{2005} & SIS & 9,5 & 3,0 & 31,4 & 3,9 & 8,8 & 0,0 & 2,7 & 40,8 & 100,0 \\
\hline & NO SIS & 23,8 & 3,7 & 22,6 & 3,4 & 4,4 & 0,7 & 1,2 & 40,2 & 100,0 \\
\hline \multirow{2}{*}{2006} & SIS & 10,8 & 3,6 & 34,6 & 5,4 & 8,3 & 0,0 & 2,4 & 34,9 & 100,0 \\
\hline & NO SIS & 23,0 & 3,9 & 27,4 & 3,6 & 4,2 & 0,7 & 1,2 & 36,1 & 100,0 \\
\hline
\end{tabular}




\begin{tabular}{|c|c|c|c|c|c|c|c|c|c|c|}
\hline & & $\begin{array}{l}\text { Falta de } \\
\text { dinero }\end{array}$ & $\begin{array}{c}\text { Maltrato, falta } \\
\text { de confianza, } \\
\text { demoran en } \\
\text { atender }\end{array}$ & $\begin{array}{c}\text { Remedios } \\
\text { caseros, } \\
\text { autorreceta }\end{array}$ & $\begin{array}{l}\text { Falta de } \\
\text { tiempo }\end{array}$ & $\begin{array}{c}\text { Distan- } \\
\text { cia }\end{array}$ & $\begin{array}{c}\text { No tiene } \\
\text { seguro }\end{array}$ & Otros & $\begin{array}{c}\text { Otras } \\
\text { combina- } \\
\text { ciones }\end{array}$ & Total \\
\hline \multirow{2}{*}{2007} & SIS & & 4,8 & 30,2 & 6,9 & 7,5 & 0,0 & 2,4 & 33,8 & 100,0 \\
\hline & NO SIS & 26,9 & 5,1 & 23,2 & 4,7 & 3,9 & 1,5 & 1,4 & 33,3 & 100,0 \\
\hline \multirow{2}{*}{2008} & SIS & 12,6 & 7,3 & 24,7 & 10,3 & 6,4 & 0,0 & 4,2 & 34,4 & 100,0 \\
\hline & NO SIS & 24,3 & 5,4 & 21,8 & 6,5 & 3,8 & 1,4 & 2,1 & 34,7 & 100,0 \\
\hline \multirow{2}{*}{2009} & SIS & 11,0 & 7,7 & 26,0 & 10,1 & 6,3 & 0,0 & 4,6 & 34,3 & 100,0 \\
\hline & NO SIS & 17,6 & 6,8 & 16,6 & 8,2 & 14,6 & 2,4 & 2,5 & 31,2 & 100,0 \\
\hline \multirow{2}{*}{2010} & SIS & 8,9 & 8,0 & 22,9 & 9,9 & 6,8 & 0,0 & 6,2 & 37,2 & 100,0 \\
\hline & NO SIS & 14,8 & 7,3 & 18,0 & 9,5 & 4,9 & 4,2 & 3,2 & 38,0 & 100,0 \\
\hline \multirow{2}{*}{2011} & SIS & 8,6 & 7,5 & 22,8 & 9,4 & 5,4 & 0,0 & 6,4 & 39,9 & 100,0 \\
\hline & NO SIS & 11,3 & 6,4 & 18,1 & 8,3 & 5,1 & 4,8 & 3,7 & 42,4 & 100,0 \\
\hline \multirow{2}{*}{2012} & SIS & 7,2 & 8,2 & 21,9 & 8,8 & 5,3 & 0,0 & 5,8 & 42,8 & 100,0 \\
\hline & NO SIS & 9,5 & 7,3 & 19,5 & 6,8 & 3,7 & 4,7 & 3,7 & 44,8 & 100,0 \\
\hline \multirow{2}{*}{2013} & SIS & 6,5 & 7,8 & 21,8 & 8,4 & 6,8 & 0,0 & 7,8 & 40,9 & 100,0 \\
\hline & NO SIS & 9,9 & 6,7 & 18,9 & 7,4 & 6,1 & 5,1 & 5,3 & 40,6 & 100,0 \\
\hline \multirow{2}{*}{2014} & SIS & 6,3 & 7,3 & 22,9 & 8,6 & 5,9 & 0,0 & 5,5 & 43,5 & 100,0 \\
\hline & NO SIS & 8,1 & 7,1 & 22,2 & 7,2 & 5,1 & 4,8 & 2,9 & 42,5 & 100,0 \\
\hline
\end{tabular}

Fuente: Base de datos de Minsa (2015) y actualización propia.

\subsection{Medicamentos}

Es conocido el rol estratégico que tiene el medicamento para la eficacia de la atención de salud. A ello se agrega el importante peso que tiene en la definición de la capacidad real de compra de servicios de salud tanto desde los proveedores públicos como desde los hogares, lo que lo torna en un tema de suma importancia en la salud pública.

A nivel nacional, una estimación referencial ${ }^{23}$ del estudio calcula que para $2012 \mathrm{el}$ valor de ventas del mercado farmacéutico era de US\$1891,1 millones de los cuales el $61,8 \%$ estaba constituido por el denominado sector retail (farmacias y boticas que venden directamente al público); 14,4\% por el sector institucional privado (mayormente clínicas que venden a sus usuarios); y el $22,8 \%$ por el sector institucional público (prestadores del Minsa, EsSalud, sanidades, municipios y beneficencia) (Gráfico 14). La tendencia en valores resulta creciente para el sector retail que se expande sobre todo con la estrategia de cadenas que apunta a un nivel de integración vertical y está asociada al crecimiento económico.

23 Ver restricciones en Minsa (2015, pp. 114, 115). 
Gráfico 14. Estimación de ventas del mercado farmacéutico por sectores. Perú 2012

$(\%)$

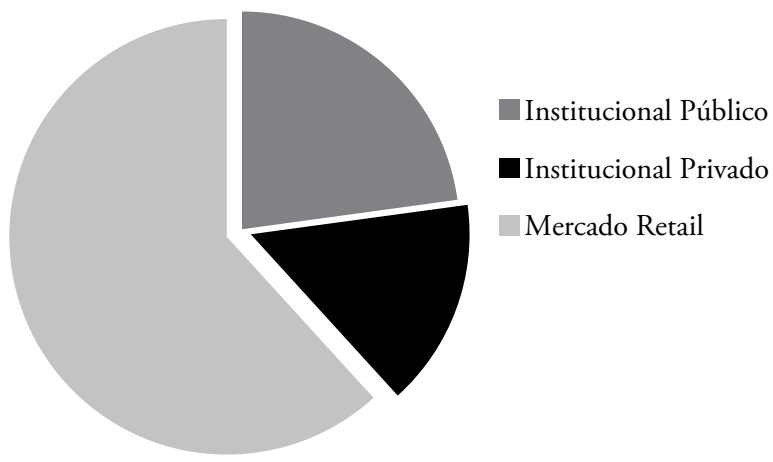

Fuente: Cuadro 7.

Entre los años 2007 y 2012 el gasto en medicamentos del sector público pasó de 225,6 a 432,1 millones de dólares estadounidenses, y mantuvo su estructura con excepción de una mayor participación del Minsa y disminución de las Regiones (Cuadro 13). No obstante, el principal aporte radica en la política de consumo masivo de medicamentos genéricos, lo que implica, según el Observatorio de Precios de Medicamentos, una diferencia en el precio al público de hasta cuatro veces entre un medicamento genérico y uno de marca. Un segundo aporte ha sido la política de compras corporativas con la modalidad de subasta inversa, a la que se han ido sumando otras entidades del sector público. Entre los ańos 2008 y 2013, ha permitido un ahorro de 283,7 millones de nuevos soles aunque ha ido disminuyendo a lo largo del periodo, lo que podrá sugerir un agotamiento de la estrategia (Minsa, 2015, pp. 121, 122).

\section{Cuadro 7}

Presupuesto público ejecutado en medicamentos según prestador. Perú, 2007-2012 (En porcentaje, millones de nuevos soles y millones de US\$)

\begin{tabular}{l|r|r|r|r|r|r}
\hline & $\mathbf{2 0 0 7}$ & $\mathbf{2 0 0 8}$ & $\mathbf{2 0 0 9}$ & $\mathbf{2 0 1 0}$ & $\mathbf{2 0 1 1}$ & $\mathbf{2 0 1 2}$ \\
\hline Minsa & 29,5 & 23,5 & 36,2 & 36,9 & 31,1 & 32,7 \\
Regiones & 14,1 & 14,0 & 11,2 & 10,2 & 12,2 & 10,3 \\
Minsa + Regiones & 43,5 & 37,5 & 47,4 & 47,1 & 43,4 & 43,0 \\
Sanidades & 2,2 & 1,6 & 1,1 & 1,7 & 1,1 & 1,5 \\
Otros públicos (beneficencias) & 0,8 & 0,8 & 0,9 & 0,6 & 0,7 & 0,6 \\
Local (municipalidades) & 0,3 & 0,4 & 0,3 & 0,4 & 0,5 & 0,5 \\
ESSalud & 53,2 & 59,6 & 50,2 & 50,2 & 54,3 & 54,4 \\
\hline Total público (\%) & 100,0 & 100,0 & 100,0 & 100,0 & 100,0 & 100,0 \\
Total público (millones nuevos soles) & 706,0 & 713,7 & 988,3 & 1089,1 & 996,1 & 1139,9 \\
Total público (millones US\$) & 225,6 & 243,9 & 328,1 & 385,4 & 361,6 & 432,1 \\
\hline
\end{tabular}

Fuente: Minsa (2015, p. 120). 


\section{REFLEXIONES FINALES PARA LA RECTORÍA}

El problema de la salud es multisectorial por lo que para mejorar la salud de la población se requiere de intervenciones conjuntas en educación, nutrición, saneamiento, transporte, entre otros ámbitos. Siendo eso importante no lo estamos estimando acá. Este artículo se ocupa de los servicios de salud, que es el otro lado de la cara de la moneda de cómo mejorar la salud de la población.

a) Considerar que el Perú gastó solo el 5,2\% de su PIB en la atención de servicios de salud en el año 2012, va más allá de señalar la existencia de un subfinanciamiento del gasto; debe ser considerado como una oportunidad para estimar el tipo de crecimiento, el "cómo se quiere crecer», que el país necesita para lograr el objetivo de acceso universal que se han propuesto el Estado peruano y la sociedad civil (Acuerdo Nacional, 2015). El «cómo» es la combinación adecuada de la contribución de los agentes del financiamiento, su intermediación y mancomunación en fondos de aseguramiento y la organización de la prestación deseada acorde con los objetivos políticos acordados, la situación del país, la de su gente, y las tecnologías disponibles.

b) El crecimiento del gasto en salud depende del crecimiento económico, de la voluntad política y de la capacidad de organización y rectoría en salud. De una manera simplificada: el crecimiento económico aumenta la masa tributaria y el Estado tiene mayores recursos financieros para gastar, con lo que se acrecientan los recursos públicos en salud. Igualmente, amplía el empleo formal y con ello los asegurados y los recursos a la seguridad social en salud. Los hogares logran mayor ingreso y se incrementan sus recursos para gastar, con lo cual hay más espacio para el ingreso al mercado de los prestadores privados. En este devenir, si además el Estado tiene la voluntad y un plan para desarrollar la atención de salud de la población, no solo incrementará sus recursos, sino que intervendrá activamente en la organización del financiamiento y la prestación buscando, además, interactuar con el sector privado. Ello ha venido ocurriendo en el Perú, pero resulta insuficiente.

c) El financiamiento de la salud en Perú tiene principalmente tres fuentes: gasto de los hogares, recursos del tesoro público y cotizaciones a la seguridad social en salud a partir del $9 \%$ de la remuneración declarada en planilla por los empleadores $^{24}{ }^{25}$. Si bien las tres fuentes han crecido en términos absolutos, el cambio más importante en la estructura de financiamiento ha sido el aumento fiscal

\footnotetext{
24 En Perú, no existe un aporte fiscal a la seguridad social; ella es financiada en su totalidad por los aportes sobre la base de las remuneraciones declaradas en la nómina.

25 La exoneración del pago de contribuciones a EsSalud por las gratificaciones de julio y diciembre desde 2009, ha sido una medida bastante controversial que puso en la discusión la pérdida de dichos ingresos a EsSalud versus el mayor ingreso en el bolsillo de los trabajadores al evitarse dicha deducción. Subyacente a esta discusión está la valoración a los servicios que presta EsSalud, sobre todo debido a problemas de acceso y efectividad de la atención a los trabajadores afiliados.
} 
(tesoro público) en salud, sobre todo desde 2005, del que pasó, del 26,5\% al 29,0\%, destinado fundamentalmente al Minsa y las Regiones, acelerando el lento y sostenido descenso del financiamiento de los hogares que disminuyó hasta el $37,0 \%$, mientas que los aportes a la seguridad social subieron al 30,1\% debido al incremento en remuneraciones, pero también a un muy lento incremento de la formalidad laboral, siendo Perú uno de los países con mayor informalidad ${ }^{26}$.

¿Cuáles son las metas? Para garantizar el objetivo del acceso y cobertura universal, Perú, como país miembro de la OPS, ha suscrito la estrategia correspondiente (OPS, 2014). En ella se estima que, progresiva y conjuntamente con la mejora en la eficiencia del financiamiento, el financiamiento público conjuntamente con el financiamiento mancomunado obligatorio, arriben al $6 \%$ del PIB, a la par que disminuya la participación del gasto de bolsillo a no más del $15 \%$ a $20 \%$ del total del financiamiento, por ser este regresivo, excluyente, no solidario, ni permitir anticipar las ocurrencias de enfermedad o accidente en salud (OPS, 2015, pp. 13-14; OMS, 2010). La existencia de un Acuerdo Nacional ya mencionado, como política de Estado, es un elemento político a favor, en un contexto de disminución del ritmo de crecimiento económico, lo que reclama gradualidad y medidas de eficiencia ${ }^{27}$ en la gestión del sistema sanitario a nivel global, nacional, regional y local a la par que la apertura de nuevos espacios fiscales, referidos a mecanismos tributarios y a la contribución obligatoria a la seguridad social. La tarea para la rectoría en salud se vuelve más ardua: debe ser capaz de visibilizar las ganancias concretas de un mayor financiamiento en salud en metas objetivas, evaluables y evaluadas.

d) El porcentaje del financiamiento intermediado por un fondo o seguro subió de 30,7 a $37,4 \%$. Sobre todo ocurrieron cambios cualitativos: (a) la ruptura del monopolio de la prestación de EsSalud como entidad aseguradora y prestadora de la seguridad social, con el surgimiento de aseguradoras asociadas a prestadores privados (EPS); (b) la creación de la Superintendencia de EPS, que devino en la Superintendencia Nacional de Salud (Susalud), entidad reguladora que tiene como función y reto principal proteger los derechos en salud de los ciudadanos, independientemente del lugar de atención o su condición de aseguramiento; y, sobre todo, (c) el paulatino crecimiento del Seguro Integral de Salud (SIS) seguro público enfocado en la población en pobreza. En 2012, del 100\% del financiamiento agrupado en fondos, EsSalud tenía el 69,0\%, las EPS más los seguros privados el $20,8 \%$, los autoseguros el 4,5\% y el SIS el 5,6\% restante.

\footnotetext{
26 Entre los ańos 2007 y 2012, el INEI (2014) reportó el descenso de 79,7\% a 74\% de la fuerza laboral que trabaja fuera del sector formal.

27 OMS ha estimado que cerca del $20-40 \%$ de los recursos utilizados en el mundo en la salud se malgastan (OMS, 2010, XVIII.
} 
e) En el gasto, el principal cambio en la gestión pública ha sido la descentralización y en la gestión privada la integración vertical de prestadores y aseguradoras, dando surgimiento a un agente nuevo: el inversionista en salud. Aún así, y debido al continuo incremento en el financiamiento por el tesoro público, el gasto en prestadores públicos aumentó más que el efectuado en el sector privado (2005-2014).

f) No obstante, el aumento del financiamiento, y con él el del gasto, es solo uno de los requisitos para ampliar el acceso a los servicios de salud. Entre el 2004-2012, el incremento de usuarios de los servicios de salud del Minsa y regiones fue limitado, subió de 2,6 a 3,0 millones de personas, pero disminuyó porcentualmente su participación en la utilización de servicios de salud, mientras se incrementó la utilización en el sector privado, pese al notable esfuerzo del tesoro público, que en dicho periodo aumentó en $244 \%$ en valores reales en beneficio Minsa y Regiones. Se identifican algunos factores, vinculados a la gobernanza, organización y gestión de los servicios, que pudieron frenar la capacidad de respuesta del sistema: (a) la dificultad de gobernanza con las regiones en el marco de un proceso de descentralización inconcluso debilitó la coordinación y la rectoría del Minsa; (b) problemas con los recursos humanos (huelgas, escasez, reticencia, pese a incentivos a trabajar fuera de grandes ciudades); (c) la inadecuada gestión pública de la inversión (lentitud y baja coordinación con el gasto corriente); y,(d) los mecanismos de contención en los prestadores ante la fuerte presión de demanda por el aumento de los afiliados al SIS de 4,1 a 9,1 millones.

g) El incremento en la utilización de los prestadores privados y de la farmacia/botica como lugares de consulta y compra de medicamentos sin pasar previamente por un prestador de servicios se debió tanto al crecimiento económico y mayor disponibilidad de ingreso de los hogares, como a una activa política privada de expansión de cadenas de farmacias y de servicios de salud, con un núcleo moderno de integración vertical, al menor aprovechamiento del crecimiento económico de parte del sector público debido a los problemas anteriormente enunciados.

h) A nivel poblacional, entre los ańos 1995-2012, han ocurrido dos grandes cambios en el aseguramiento en salud. Primero, cuantitativamente, pasó de $24 \%$ a $62 \%$ de la población y segundo, más de orden cualitativo, con el surgimiento del SIS, este ha llegado a agrupar un poco más de la mitad (51\%) del total de asegurados (2012). No obstante, se advierten las siguientes tensiones:

i) No todos los afiliados a un seguro acceden a sus prestadores y servicios, recurriendo a la consulta directa en farmacia o no logrando atención. Esto ocurre, con independencia del tipo de seguro y evidencia problemas de oferta, gestión y de objetivos. 
ii) En cuanto al SIS, si bien ha logrado incrementar el acceso a los servicios de salud y mejorar la protección financiera al disminuir el gasto de bolsillo de la población en pobreza afiliada que accede a los servicios de salud, parte importante de la población no logra acceder, lo que violenta el derecho ofrecido.

iii) Pese a los diversos intentos de captación, la afiliación a seguros semicontributivo SIS o independiente (EsSalud) de la población informal no pobre es muy escasa, lo que requiere profundizar su estudio desde una perspectiva económica y social centrada en el trabajador independiente con capacidad de pago.

i) Esta limitada correspondencia entre estar afiliado a un seguro y poder acceder a los servicios que teóricamente deben brindarse, expresa severas restricciones en la oferta pública y en el sistema de salud en general, difíciles de suplir (aunque no de complementarse) con una oferta privada contratada. La transformación del sistema de atención pública del Minsa/Regiones y de EsSalud es un requisito para que las poblaciones afiliadas al SIS y a EsSalud adquieran la seguridad de contar con una atención garantizada. Si bien en aquellos que cuentan con un seguro privado el acceso a consultorios y clínicas fue algo mayor al del SIS y EsSalud, un $19,8 \%$ recurrió a farmacias y boticas para consulta y compra de medicamentos y el $28,4 \%$ no accedió, posiblemente debido a las exclusiones y falta de dinero suficiente para los copagos. Es una recomendación de política poner los seguros al servicio de sus afiliados, siendo este, posiblemente, el principal reto de Sunasa como entidad reguladora.

j) El SIS juega un importante rol como brazo financiero de la rectoría nacional para con la atención y en parte del gasto corriente de la población más vulnerable. Aunque cuenta con avances en sus mecanismos de compra de servicios y de supervisión, todavía, tiene pendiente temas importantes en su organización, sobre todo en su función de compra de servicios, cuya decisión descansa en la rectoría del Minsa, pero también en la voluntad política. Así, debería ser parte de la discusión si el ser el encargado de la función de compra pública, implica que el SIS debe transitar de financiar solo el gasto corriente estratégico (medicinas e insumos y algunos gastos de gestión) a manejar el total del gasto corriente y remuneraciones. Consecuentemente esta función de compra debe estar sustentada en indicadores de gestión asociados a resultados sanitarios. De otro lado, se requiere definir el sistema de costos, así como si las necesidades financieras del aseguramiento público deban ser estimadas sobre la base del cálculo actuarial y este servir de insumo para estructurar el presupuesto por resultados, metodología adoptada por el Ministerio de Economía y Finanzas para el gasto público. 
k) La eficiencia global del sistema aumentaría con el desarrollo de mecanismos e instrumentos de integración financiera entre EsSalud y el SIS, como compartir el mismo sistema de información, incluyendo costos, compra de medicamentos de alto costo y mancomunación de ciertos fondos.

1) El gasto directo o de bolsillo representa cerca al $90 \%$ del gasto de los hogares en salud. Si bien este gasto se incrementó, asociado al aumento en su ingreso, lo hizo en mucha menor proporción en aquellos en situación de mayor pobreza, lo que estuvo asociado a la alta afiliación al SIS. Los medicamentos son el principal rubro de gasto de bolsillo (43-47\%) de los hogares durante el periodo 2004-2012. $\mathrm{Si}$ bien la mayor parte del gasto de los hogares se realiza en los establecimientos privados, el estudio revela que la consulta en establecimientos públicos tiene el efecto de elevar la demanda en el sector privado porque dentro del sector público no se completa el circuito de atención (en cuanto a insumos, pruebas, medicamentos) de parte de los pacientes que a él acuden. lo que conlleva la necesidad de revisar la disposición de tecnología (equipos disponibles, medicamentos y demás, insumos) que incluye la política de abastecimiento y venta de las farmacias del Minsa Nacional y de EsSalud.

m) En el tema del medicamento, existen apreciables vacíos de información y gestión que permitan asegurar la seguridad y eficacia de los medicamentos que se registra. No solo existen problemas en los acuerdos internacionales de libre comercio sobre el tiempo de duración de patentes y segundo uso, siendo lo esperado mantener las Excepciones de $\mathrm{Doha}^{28}$; el asunto principal es hacer de la Dirección General de Medicamentos, Insumos y Drogas (Digemid) una entidad competente en información y gestión del medicamento, lo que es parte de la función rectora.

n) Finalmente, la capacidad de respuesta de un sistema sanitario dependerá no solo de un mayor y mejor financiamiento y gasto, sino también del compromiso político del Estado, instituciones y hogares y de la capacidad de gestión basada en resultados sanitarios que, además, deberá fortalecer el quehacer intersectorial en beneficio de la salud y del bienestar de la población. A ello apunta el documento suscrito por el Estado peruano como país miembro de OPS (2014), ya referido anteriormente.

${ }^{28}$ La autorización de la Organización Mundial del Comercio a no respetar patentes por razones de salud pública. 


\section{REFERENCIAS BIBLIOGRÁFICAS}

Acuerdo Nacional (2015). Los Objetivos de la Reforma de Salud. Tríptico. Lima: Secretaria Ejecutiva del Acuerdo Nacional. 22 octubre.

Gakidou, E., R. Lozano, E. Gonzalez-Pier, J. Abbott-Klafer, J. Barofsky, C. Bryson-Cahan, D. Feehan, D. Lee, H. Hernández-Llamas y C. Murray (2007). Evaluación del impacto de la reforma mexicana de salud 2001-2006. Informe Inicial. Salud Pública de México, 49(Supl. 1), 88-109.

Heijink, R., X. Xu, P. Saksena y D. Evans (2011). Validity and Comparability of out of Pocket Health Expenditure from Household Surveys: A review of de literature and current survey instruments. Discussion Paper, Number 1. HSF/DP.E.11.1. Ginebra: World Health Organization.

Instituto Nacional de Estadística e Informática (INEI) (2015). Producción y empleo informal en el Perú. Cuenta satélite de la economía informal 2007-2012. Lima. Disponible en https:// www.inei.gob.pe/media/MenuRecursivo/publicaciones_digitales/Est/Lib1154/libro.pdf

Minsa (2013). Lineamientos y medidas de reforma del sector salud. Lima: Ministerio de SaludConsejo Nacional de Salud.

Minsa OPS/OMS (2015). Cuentas Nacionales de Salud, Perú 1995-2012. Lima.

OMS (2000). Informe sobre la Salud en el Mundo 2000. Mejorar el desempeño de los sistemas de salud. Ginebra: World Health Organization.

OPS (2014). Estrategia de acceso universal y cobertura universal de salud (CD53/5, Rev.2) Washington DC. Octubre.

Perticará, M. (2008). Incidencia de los gastos de bolsillo en salud en siete países latinoamericanos. Serie Políticas Sociales 141. Santiago de Chile: División de Desarrollo Social. CEPAL. Disponible en http://hdl.handle.net/11362/6146

Petrera, M. (2012). Aseguramiento en salud en el Perú ¿Existe un efecto inclusivo del seguro público en salud? Berlín: EAE.

Stiglitz, J. (1995). La economía del sector público. Segunda edición. Barcelona: Bosch.

Documento recibido el 8 de junio de 2016 y aprobado el 4 de octubre de 2016 